\title{
Robots for Minimally Invasive Diagnosis and Intervention
}

\author{
M. Nazmul Huda ${ }^{\mathrm{a}}$, Hongnian $\mathrm{Yu}^{\mathrm{b}, *}$, Shuang Cang ${ }^{\mathrm{b}}$ \\ ${ }^{a}$ Cranfield University, Cranfield, Bedfordshire MK43 OAL, United Kingdom \\ ${ }^{b}$ Talbot Campus, Bournemouth University, Poole BH12 5BB, United Kingdom
}

\begin{abstract}
Minimally invasive diagnosis and interventions provide many benefits such as higher efficiency, safer, minimum pain, quick recovery etc. over conventional way for many procedures. Large robots such as da-Vinci are being used in this purpose, whereas research of miniature robots for laparoscopic and endoscopic use, are growing in the recent years. A comprehensive literature search is performed using keywords laparoscopic robot, capsule endoscope, surgical medical robot etc. primarily for the time period of 2000 to 2015. The articles relevant to the theme of the paper are reviewed and included in the paper. This paper concentrates medical robots for minimally invasive diagnosis and intervention in general and propulsions of miniature robots in particular. Robots are classified and compared using critical characteristics and summarized in Tables 1 to 6. Large robots such as da-Vinci are successfully used in many procedures e.g. neurosurgery, cardiothoracic surgery etc. However there are needs for more functionality which might lead to flexible robots. For miniature robots, each propulsion mechanism has some advantages and disadvantages. While external magnetic propulsions have potential to provide propulsion without increasing the robot size, they lack of precise position control and may require expensive and bulky equipment. On the other hand internal propulsions have the capa-
\end{abstract}

\footnotetext{
*Corresponding author

Email addresses: nazmul.huda@cranfield.ac.uk, nhuda@bournemouth.ac.uk (M.

Nazmul Huda), yuh@bournemouth.ac.uk (Hongnian Yu), scang@bournemouth.ac.uk (Shuang Cang)
} 
bility of precise position control but require mechanisms which need substantial amount of power to drive. Hybrid propulsion which combines best features of both internal and external propulsions could be a solution for this. Robots have improved the healthcare services for many medical procedures. However, still there are challenges to address to enable use of medical robots universally inside and outside hospitals for diagnosis and interventions.

Keywords: Medical robot, capsule endoscopy, laparoscopic surgery, propulsion mechanism, in-vivo miniature robot, minimally invasive surgery.

\section{Introduction}

Robots came into reality from fantasy world in 1961 when general motors introduced Unimate in the automobile assembly line. Subsequently robots are used in many applications such as industry, military, health care, search and 5 rescue mission, deep sea and space exploration etc. Since the first use of medical robots in 1985 to conduct stereotactic brain biopsy, the growth of robotics in health care is impressive [1, 2]. In healthcare robotics five themes are identified in [3]: (a) robot assisted preventive therapies and diagnosis; (b) robotic assistive technology; (c) robots supporting professional care; (d) robotics for rehabilita-

10 tion treatment; (e) robotics for medical interventions. This paper reviews (e) and part of (a) i.e. robotics for medical interventions and diagnosis which are minimally invasive. This paper aims to review the state of the art of minimally invasive diagnosis and interventions (e.g. surgery, biopsy), to identify the challenges in this field, to find the current trends and to provide guidance for future 15 research.

The contributions of the paper are (i) identifying the key needs and challenges of medical robots (section 2); (ii) comparing the external large robots and in-vivo miniature robots based on key features (Table 1); (iii) presenting major external large robots with important aspects (section 4); (iv) classifying 20 the miniature in-vivo laparoscopic robots, describing them with critical details and comparing them based on crucial characteristics (section 5); (iv) classifying 
the miniature in-vivo endoscopic robots, describing them with critical details, comparing them based on significant characteristics and analyzing their advantages and disadvantages (section 6); and (v) providing the future directions of external large robots and miniature in-vivo robots (section 7 ).

This paper is structured as below. Section 2 provides the needs and challenges of medical robots; section 2.2 provides challenges of external large robots, miniature in-vivo laparoscopic robots and miniature in-vivo endoscopic robots individually. Section 3 presents the classification of minimally invasive diagnosis so and intervention robots based on size and purpose; section 4 provides the background of external large surgery robots and reviews the major large robots developed primarily for robot-assisted surgery; section 5 provides the background of miniature robots for laparoscopic assistance and reviews the robots designed and built for this purpose; section 6 provides the background of miniature invivo endoscopic robots and reviews the robots designed and built to provide propulsion capability to conventional capsule endoscope and, finally section 7 provides conclusions and future trends.

\section{Needs and Challenges of Medical Robots}

\subsection{Needs of Medical Robots}

Robotics for healthcare is defined as the systems capable of doing mechatronic actions based on the analysis of sensor information to provide healthcare such as to perform medical diagnosis and interventions, to deliver treatments, to support rehabilitation, to support patients in prevention programs etc. The requirements and needs of medical robots can be seen from the viewpoints of various stakeholders namely the patients, the professional users (e.g. doctors, nurses), cure and care institutions (e.g. hospitals), insurance companies, researchers etc. The needs are provided below 2, 3, 4, 5]:

1. Safety: From the patient point of view safety is the most important requirement. Healthcare professionals (e.g. doctors, nurses) are keen to maintain safety because of their obligation towards the patients and also 
to maintain their reputation. Thus the procedures performed by the robots or with the help of robots needs to be safe for the patient and the healthcare professionals. Medical robots offer newer, better and safer treatments compare to the traditional approaches in many procedures.

2. Quality: Care institutions and medical professionals are interested in improving the quality of diagnosis and treatments. Medical robots can help in improving quality of treatments.

3. Accuracy and consistency: Medical robots can perform the surgical procedures with precise geometric accuracy. It is consistent, untiring and stable while performing the surgery.

4. Medical care in remote areas and disaster scenarios: Robots can enable access to medical care in remote areas, space missions, undersea or underground environment and disaster scenarios where medical facilities are not available. A light-weight, flexible and modular co-operative semiautonomous robot-team can be carried to the above mentioned environment and can be tele-operated by surgeons remotely.

5. Enhanced documentation: Robot assisted procedures have enhanced capability to log more detailed information about each individual case than the conventional procedures. This enables easy performance analysis and contributes to the future developments.

6. Minimally invasive procedure: Some traditional medical procedures (e.g. probe endoscopy) and treatments are painful and burdensome to the patients. Thus medical robots which introduce minimally invasive procedure are being adopted by the hospitals and doctors.

7. Efficiency: Some governments and countries are interested to make the cure and care institutions more efficient. Some medical procedures using a robot system are more efficient compare to the traditional approach. Thus by adopting medical robots care institutions can improve efficiency.

8. Quick recovery: Quick recovery is one of the important requirements for both the patients and the healthcare professionals. By using minimally 
invasive and efficient robot systems in medical procedures quicker recovery is possible.

9. Cheaper healthcare cost: To make the healthcare accessible to the people of all social classes, healthcare cost should go down. Though the initial cost for many robot systems are quite high, the added benefits such as the efficient operation, quick recovery time and less hospital stay may make the overall cost of healthcare cheaper.

10. Inaccessible environment: Medical robots enable the healthcare professionals to perform medical procedures in inaccessible areas inside the patient without major incisions.

11. Independent living: Patients such as disabled people and elderly wants to live an independent life. Robot systems can assist them to perform their daily activities independently.

12. Social participation: Social participation of disabled people and elderly are hampered in many cases due to lack of mobility and communication. Robot systems can help in improving their mobility and communication.

13. Ageing population: Because of the post-world war II baby boom the aged population percentage will increase next two to three decades with an annual growth rate of $2.8 \%$ [ 6 . The ageing problem demands increased medical and social care.

14. Economic factors: Historically healthcare spending grows faster than the economy. Innovation is required especially in robotics to sustain this spending growth in the near future where healthcare professionals will be outnumbered by the number of aged population.

\subsection{Challenges}

The challenges for a) external large robots b) in-vivo laparoscopic robots and c) in-vivo endoscopic robots individually are discussed below:

Challenges of external large robots. The following challenges have been identified [6, 7]: 
1. Localization of pathology: A robot system should have the capability to match the pre-operative diagnostic data with the surgical environment.

2. Real-time tissue characterization: To identify the pathology real-time the robot system should be able to characterize the tissue in real-time.

3. Modelling tissue deformation: Tissue deformation occurs during medical procedures by surgical tools or physiological processes. Modelling this deformation is a major challenge.

4. Restricted vision: It is challenging to get the depth of perception from the restricted vision available from the camera. To enhance the safety and reliability of the robot-assisted procedures a better coordination between the surgeon and the robot system is required.

5. Light-weight: The overall robot system is bulky and requires large operating environment. The challenge is to make it light weight and add more flexibility to the system.

6. Flexible access platforms: The tools used in the robot-assisted procedures are rigid and effective workspace is limited. Flexible access platforms could be a solution to this issue. Bio-inspired materials such as artificial muscles can help in flexible access surgery as they can work both as an actuator and sensor.

Challenges of in-vivo laparoscopic Robots. The following challenges for developing in-vivo laparoscopic robots have been identified [8, 9, 10]:

1. Propulsion system design: The primary challenge is to design a propulsion system for the stable movement of a robot. The robot should be able to navigate through the irregular, complex and sticky surface of the organs within the abdominal cavity.

2. Controllability: A control system need to be designed to control and manipulate a robot. To design the control system a model of the robot is required. The irregularity and complexity of the structure inside human body make the modelling very challenging. 
3. Size and weight: The size of robots should be small enough so that it can be inserted through a standard laparoscopic port (12 mm in diameter [1]]) and the weight of robots should be light enough so that the organs can withstand it.

4. Safety and reliability: Contact and movement of a robot should cause no damage to the inner organs.

5. Observability (vision): Physicians must be able to visually observe interior of the abdominal cavity with the help of a robot. To achieve this, a lighting system and a camera can be integrated with the robot [10].

6. Power source: To design a power source which can satisfy the power requirement of a mobile robot is a major challenge for mobile robots as all other modules depend upon it. This challenge is further increased by the size and structure of the mobile robots and, the safety considerations of the patient.

7. Telemetry: To design a power efficient and sufficiently high data rate wireless communication between a mobile robot and its external controller is another challenge for the researchers. While designing telemetry health and safety of the patient is also need to be considered.

Challenges of in-vivo endoscopic robots. The challenges to develop a self-propelling robot for capsule endoscopy are as follows [12, 13]:

1. Low cost: The robot needs to be cheap in price so that the capsule endoscope is disposable.

2. Small size: The robot should be small enough so that it can be integrated with the capsule endoscope.

3. Hermetically sealable: The robot should be hermetically sealable so that the patient lumen remains safe from the robot components.

4. Energy efficient: The robot should be energy efficient so that the power required to propel the robot can be supplied with very small size battery.

5. Safety: The overall technology used should be safe for the patient. 
6. Speed: The traveling speed of the robot should be high enough so that it can travel the GI track within a short period of time (less than $1 \mathrm{hr}$ ). E.g. a standard colonoscopy is performed within $20 \mathrm{~min}$ to $1 \mathrm{hr}$ [13] whereas the standard capsule endoscope takes 8-10 hrs [14] to complete its journey in the GI track.

7. Stopping/anchoring capability: The robot should be able to stop in the suspected region by overcoming the visceral peristalsis for better and longer inspection.

8. Painless travel: The robot should not hurt the internal soft-tissues. It should be able to travel through the GI track without the need of air insufflation which is necessary during standard colonoscopy. Air insufflation causes additional pain and discomfort to the patient.

9. Functionality: Vision is the primary functionality necessary for medical inspection. The physicians must be able to see the interior of the GI track through the camera. Other functionalities includes taking biopsies, localised drug delivery etc.

\section{Classification of Minimally Invasive Diagnosis and Intervention Robots}

Robots for minimally invasive diagnosis and interventions can be classified based on various perspectives: based on manipulator design, based on level of autonomy, based on targeted anatomy etc. [2]. In this paper we classify the robots based on whether the robot works from outside or inside the patient's body. The robots are primarily classified as external large robots [15, 16] and miniature in-vivo robots. The miniature in-vivo robots are further classified based on the targeted anatomy into miniature in-vivo laparoscopic robots [10, 17, 18] and miniature in-vivo endoscopic robots [12, 19]. Miniature in-vivo endoscopic robots work within the gastro-intestinal (GI) track whereas miniature in-vivo laparoscopic robots work within the abdominal or the thoracic cavity. Table 1 shows the comparison among the above mentioned robots. 


\section{External large medical robots}

\subsection{Background}

Minimally invasive diagnosis and interventions feature safe and reliable techniques and result in shorter hospital stays, less pain, more rapid return to daily work and improved immunological response compare to the conventional ways. This motivates the development of minimally invasive devices for surgical and diagnostic applications [15, 16, 20, 21, 22, 23, 24, 25]. After the appearance of laparoscopic surgery - a minimally invasive abdominal or pelvic surgery performed using laparoscopic instruments inserted through small trocars - in the middle of 1980s [26], it is expanded rapidly because of its advantages over traditional open surgery [22, 27]. To further reduce the invasiveness, robot-assisted laparoscopic and thoracoscopic surgery were introduced in early 1990s [28] which removes some of the limitations of manual laparoscopy namely hand tremor, bulky instrument handling, poor visibility etc. [29] and adds new features namely stereoscopic vision, motion scaling, increased degrees of freedom etc. [30, 31]. Robot-assisted surgery is performed by a multi-arm robot which is tele-operated by a surgeon. Each arm of the robot can manipulate a tool or camera according to the command by the surgeon. However these systems are expensive, bulky, 215 heavy-weight and, needs a large operating room and significant setup time.

\subsection{Major surgical robots}

The first robot used in surgical procedure is an industrial robot, Unimation PUMA 200, in 1985 in USA. It is used to precisely guide a probe for brain biopsy using CT guidance [32]. The robot is experimentally used for 22 pa${ }_{220}$ tients and is found to improve the precision but is very crude [3]. The first robot surgical system approved by FDA (Food and Drug Administration) is the ROBODOC. Integrated Surgical Systems developed in 1992 for orthopaedic surgeries demonstrated greater accuracy as compared to the conventional ways. However it shows poor performance if the patient moves. This system is no more in production [3]. 
The other robot systems approved by FDA are AESOP, da-Vinci, Zeus etc. AESOP (Automated Optical System for Optimal Positioning) developed by Computer Motion, Inc. is a foot-switch or hand-controlled robot arm when it was first introduced. The later versions of AESOP are voice-controlled. The robot arm uses an adapter to hold laparoscope with a video camera to assist the surgeon and replace human camera holder [23]. It enables solo-surgeon laparoscopic surgery in various surgical procedures e.g. cholecystectomies, hernia repairs, colectomy etc. [33, 34]. Though AESOP provides a stable camera platform, the camera movements in voice control are slower as compared to human assistant control. Moreover voice-control might distract other members of the surgical team [23].

In another type of surgical robots based on a master/slave configuration, the robots are programmed to mimic the hand movements of the surgeon - the examples are da-Vinci, Zeus etc. The ZEUS system is developed on top of the 240 AESOP by Computer Motion. Here one voice controlled robot arm, AESOP is used for holding camera and two more AESOP-like units are modified to hold and operate surgical tools. The ZEUS system consists of a surgeons console, a surgical cart with three robotic arms and surgical instruments. The surgeon sits comfortably upright on the console and wears a polarized goggle to get a $3 \mathrm{D}$ view of the operating area and controls the robotic arms and the instruments using the handles placed in the console. The surgeons movement is scaled down, filtered and translated to the movements of the robot arms and tools. Intuitive Surgical Inc. acquired Computer Motion in 2003 and later on discontinued the production of the Zeus system [1, 23, 35].

Intuitive Surgical, Inc. developed the da-Vinci Surgical System which got FDA approval in 2000. It consists of a surgeons console, a visualization system, surgical cart with multiple robot arms and proprietary surgical instruments. The surgeons console comprises of 3D imaging system, hand controlled manipulators and foot-pedals. The surgeon operates using the hand-controlled manip255 ulators and the foot-pedals with the aid of the 3D imaging system. The robot arms are connected to the operating trocars through which the camera and the 
operating instruments are passed to the operating area inside the patient. The hand, wrist and finger movements of the surgeon are translated to the actions of the instruments inside the patient. The foot-pedals provide further control to camera focus, instrument clutches etc. The Endowrist technology enables the instruments to have seven degrees of freedom which offers greater range of motion than human hand. The 3D view provides the surgeon the illusion of being in the operating site. The supporting staffs help in preparing the trocars, installing the instruments and tools, supervising the robot arms with the aid 265 of a visualisation system. In the later version of the da-Vinci system, a fourth robot arm is added which enables the surgeon to toggle between three tools while operating $[1,15,23,36]$.

FDA has approved the da-Vinci surgical system for various surgical procedures e.g. general, urologic, gynecologic and cardiac surgeries [1]. The clinical data shows an improved or equal surgical outcome with shorter hospital stays, less pain and more rapid return to daily work for robot assisted surgery. Though the initial cost of the robot system is high (the price of da-Vinci System is approximately 1.5 million Euros), the total hospital cost for a patient is comparable to conventional laparoscopy due to less post-surgery complications. Thus increased usages of robots in surgery are seen in recent years [1]. In USA $36 \%$ of hysterectomy for benign conditions and $83 \%$ of prostatectomy were performed by the da-Vinci Surgical System in 2011 as compared to $0 \%$ and 23 $\%$ respectively in 2005 [37].

\section{Miniature in-vivo Robot: Laparoscopic Robot}

\subsection{Background}

An approach for improving patient experience during and after the surgical procedure is to send a miniature robot / a team of miniature robots entirely inside the patient body to provide the surgeon with vision and surgical task assistance. Researches show promising results in various in-vivo experiments though currently they lack precise control [10, 38]. The ultimate goal of this 
approach is to develop a multiple cooperative modular robot which together can perform a complete surgery. They are small and easily transportable [17]. They could be life-saving for remote areas e.g. battlefield and even for space mission where large medical equipment are not available. $90 \%$ of the battlefield deaths happen within 30 minutes of initial injury, long before the patients can be transported to operation theatre. $50 \%$ of deaths happen because of thoracic and abdominal haemorrhage. The wireless in vivo robots can potentially be used for initial monitoring, treatments and basic surgery before the patient can be transported to the hospital and thus be able to reduce mortality rate. The robots can be deployed by non-medical person and then a surgeon can operate it remotely to provide the medical care [39].

\subsection{Major in-vivo laparoscopic robots built}

University of Nebraska-Lincoln develops fixed-base camera robots [40, 41], mobile wheeled robots [9, 17, 38] and magnetic drive robots [42] for biopsy and, vision and task assistance during laparoscopic surgery. BioRobotics Institute, Scuola Superiore Sant'Anna, Italy develops miniature modular in vivo robots including camera robot, retraction unit and manipulator unit [43, 44]. University of South Florida develops MARVEL (Miniature Anchored Robotic Videoscope for Expedited Laparoscopy) and Camera Module [45, 46]. Other research groups working in miniature laparoscopic robots develop magnetic drive robots [47, 48, 49] and suction based robots [50, 51] for surgical assistance. Thus the in-vivo laparoscopic robots can be divided based on the propulsion capability and propulsion methods as:

- Fixed base camera robots [40, 45, 46, 52, 53]

- Wheeled robots $[9,10]$

- Magnetic drive robots [42, 43, 44, 47, 48] and

- Suction-based robots [51, 54] 


\subsubsection{Fixed base camera robots}

Fixed-base camera robots are further classified based on the method used to mount the robot within the abdominal cavity.

Tripod mounted camera robot. A fixed-base tethered camera robot (Fig. 1(a) is developed for augmenting the vision and depth perception of operating area inside the patient's body. The robot consists of a camera, two LEDs, a robot body, 3 legs which works as the tripod stand; the camera allows a 360 degree panning and a 45 degree tilting. The robot is tested during a porcine cholecystectomy. The surgeon gets supplementary vision feedback throughout the process which helps him in planning and placing the trocars and, provides better knowledge about the surgical field [40].

Needle mounted camera robot. A system named MARVEL (Miniature Anchored 325 Robotic Videoscope for Expedited Laparoscopy) is developed in [45, 46] which includes multiple fixed-base pan/tilt camera modules, a master control module and a human-machine interface. The camera module 1(c) comprises of five subsystems namely illumination, vision, wireless communication, embedded control and attachment needle power subsystems. The camera module is attached to the abdominal wall with the attachment needle power subsystem which is also used to power the camera module. Two camera modules are tested simultaneously inside the abdominal cavity of a porcine subject demonstrating transmission of images from the camera modules [45, 46].

Suturing mounted camera robot. A fixed-base surgical imaging device (Fig. 335 1(b) with pan, tilt, zoom and lighting is developed in [52, 53]. The length and diameter of the device is $110 \mathrm{~mm}$ and $11 \mathrm{~mm}$ respectively. In vivo porcine animal experiments are performed using the device which includes cholecystectomy, appendectomy, nephrectomy etc. The device is inserted into the abdominal cavity through a standard $12 \mathrm{~mm}$ trocar and mounted by suturing to the abdominal wall. 


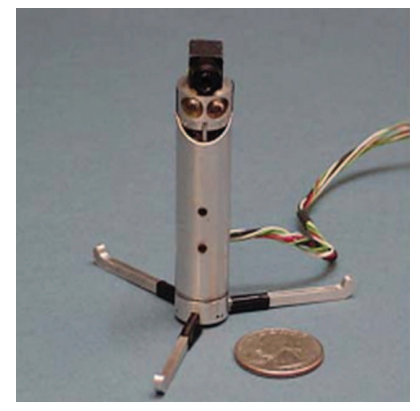

(a) Fixed base pan and tilt camera robot (tripod mounted) 55 , 40]

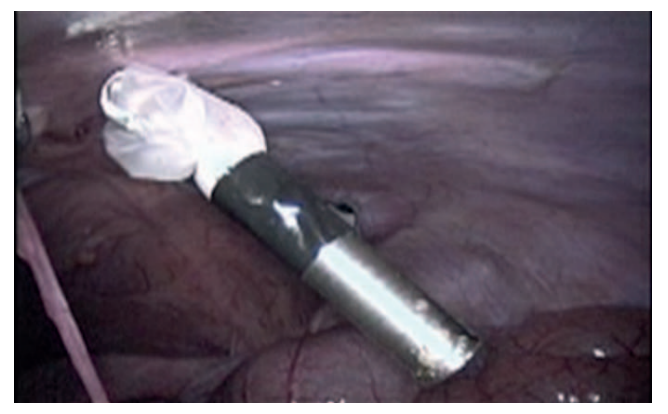

(b) Fixed base imaging device in abdominal cavity (suturing mounted) 53]
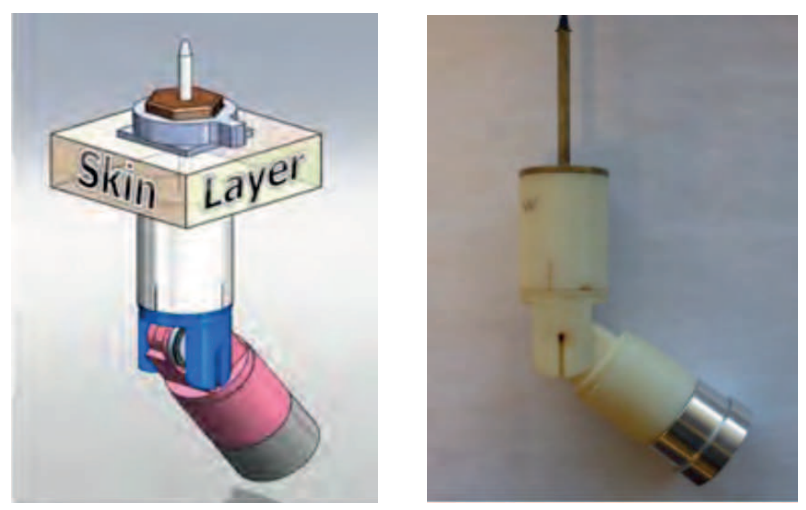

(c) Fixed base MARVEL camera module - Left: CAD design; right: prototype (needle mounted) 455, 46]

Figure 1: Fixed-base in vivo laparoscopic robots 


\subsubsection{Wheeled Robots}

Wheeled robots (Fig. 2(a) are designed and developed for supporting laparoscopic procedure in [9]. The robot consists of two independently controllable wheels, an appendage and a central region for camera. They develop robots with brush, helical, smooth, male and female type wheels. The developed prototype is $15 \mathrm{~mm}$ in diameter and $85 \mathrm{~mm}$ long. The helical wheel performs best during the in-vivo porcine tests in traversing and climbing the abdominal organs without causing tissue damage [9]. All the wheeled robots developed for surgical assistance have the similar mobility principle but various added functionalities. A mobile in-vivo wheeled camera biopsy robot is developed and tested in a porcine model in [38] shown in Fig. 2(d) Traditional biopsy requires two ports (one for camera, one for biopsy tools) for biopsy whereas this robot requires only one port as it integrates an adjustable-focus camera and biopsy tool in one unit. The robot is able to grasp the porcine tissue and free it from the organ during the test [38]. An abdominal cavity simulator is developed by Nebraska University and used in Aquarius underwater habitat where the crew members performed the surgical task (Fig. 2(d) with the aid of a fixed base camera robot and a mobile wheeled camera robot. The crew performed an appendectomy while being telementored via video conference. The results show that a miniature in-vivo camera robot can be a replacement of traditional laparoscopic camera without compromising the task accuracy [17]. In-vivo wheeled robots are developed for clamping, cauterisation and liquid delivery in [56]. Two robots perform a cooperative work - clamping robot grasps and then cautery robot cuts a portion of small bowel - where they use laparoscope for visualisation. These researches suggest that in future several miniature robots which are sent inside the abdominal cavity through single incision can perform surgical procedures cooperatively.

\subsubsection{Robots with Magnetic Drives}

Several robots namely peritoneum-mounted imaging robot (Fig. 3(a) , lighting robot, retraction robot (Fig. 3(b)] are developed in [42] to cooperatively 


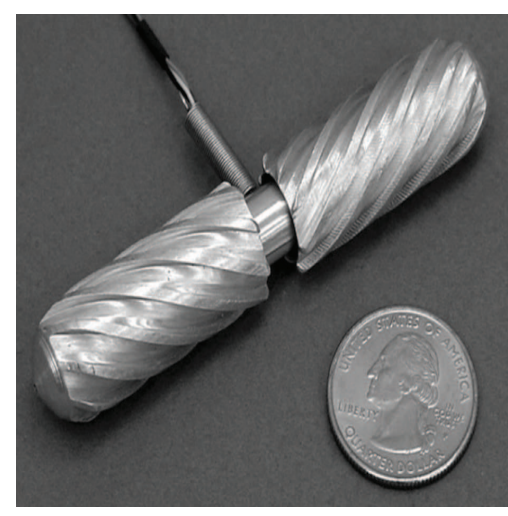

(a) Mobile wheeled robot [9]

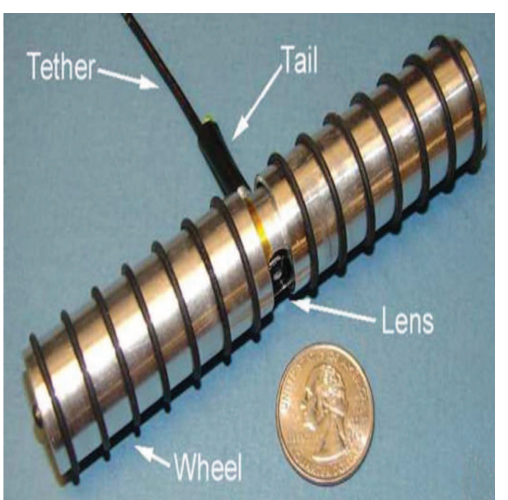

(b) Mobile camera robot 17

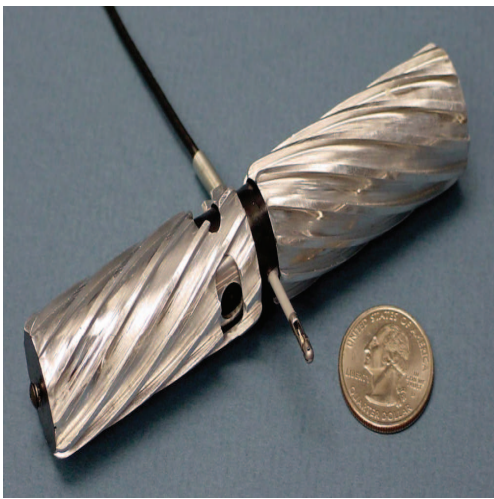

(c) Mobile camera biopsy robot 38]
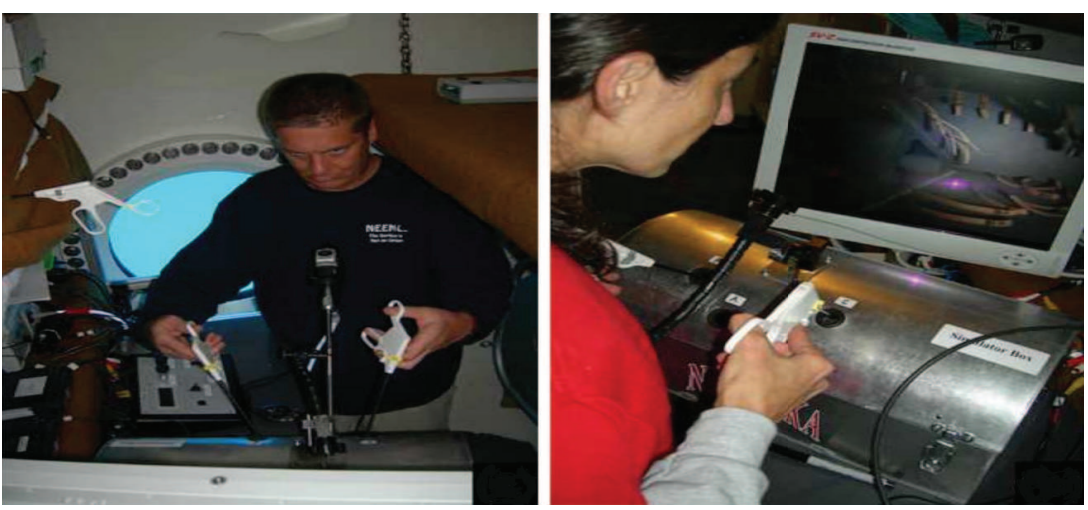

(d) Crew members of Aquarius underwater habitat performing surgical tasks with the assistance of a fixed base camera robot ( Fig. 1(a) ] and a mobile camera robot ( Fig. 2(b) ) 17

Figure 2: Wheeled in vivo laparoscopic robots 
assist in surgical procedures in laparoscopic, robot-assisted surgery or NOTES (Natural orifice translumenal endoscopic surgery). Magnets at each end of the robots and external magnetic handles are used to attach the robots to the abdominal wall and to maneuver them. Few magnetic drive robots are developed 375 in [49] where a ferromagnetic material is used inside each robot and an external magnet controlled the movement of each robot. This type of robots include robot with vision capability, robot with vision and manipulation capabilities etc.

A camera system (Fig. $3(\mathrm{~d})$ with a dimension of $32 \mathrm{~mm} \times 29 \mathrm{~mm} \times 129 \mathrm{~mm}$ is developed in [48] which is inserted through a $26 \mathrm{~mm}$ incision in the umbilicus. A magnet handle is used to suspend and move the camera along the abdominal wall. An alternative way is to mount the camera using a hook and ring arrangement and then to use the magnet handle to move the camera around the incision point [48].

An array of robots (Fig. 3(e) (electro-cutter robot, manipulator robot - diameter: 12mm, length: $95 \mathrm{~mm}$, weight: $12 \mathrm{~g}$, retraction robot-diameter: $12 \mathrm{~mm}$, length: $52 \mathrm{~mm}$, weight: $12 \mathrm{~g}$, and camera robot) are developed in [43, 44]. A triangle shaped anchoring frame with three docking systems is used to support the array of robots inside the abdominal cavity. Two external magnetic handles are used to anchor the anchoring frame and the retraction robot. The magnetic handle can be used to move the retraction robot along the abdominal wall which increase the robot's workspace. The robots can be docked and undocked during the surgical procedures if required. The complete platform is inserted into a phantom abdominal cavity through esophageal access port. Further experiments such as tissue cutting, pick and place are performed to demonstrate the interaction capability of two robots [43, 44].

A robotic system consisting of a camera robot and a robotic grasper is proposed in [47]. The end effectors of two external robotic arms holds two external magnets which control the positions of the robots inside the abdominal cavity. 


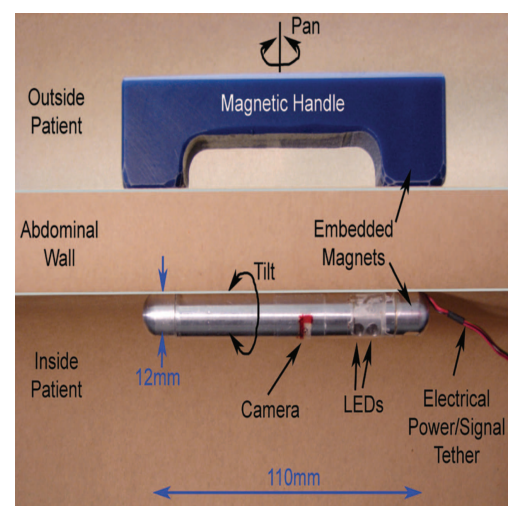

(a) Peritoneum-mounted imaging robot system 42

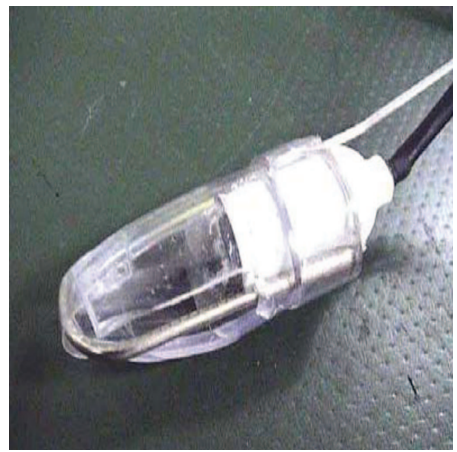

(c) In vivo magnetic drive robot: experimental model 49]
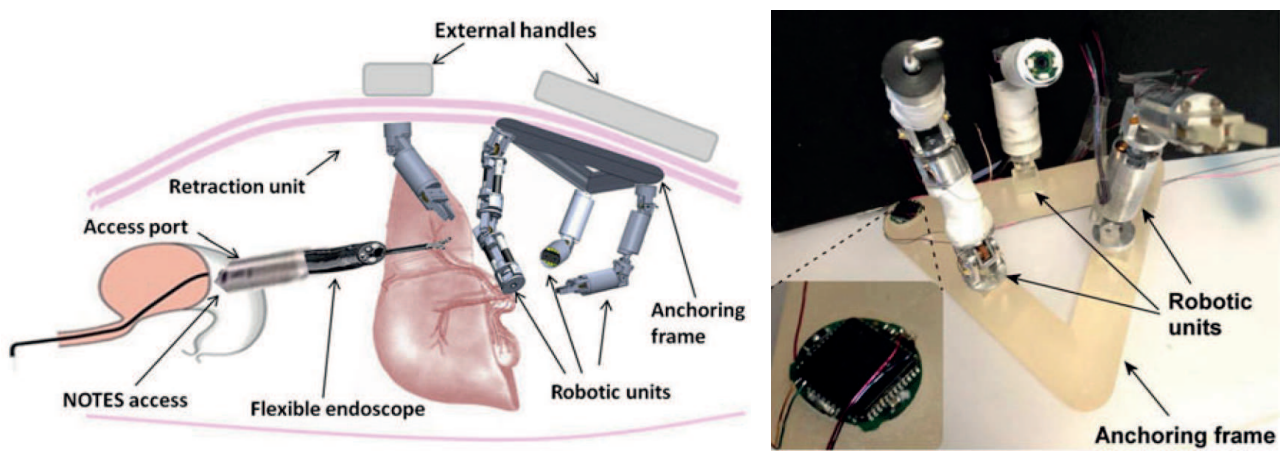

(e) In vivo magnetic drive array of robots (Left: schematic of robots within the abdominal cavity; right: prototype 43]

Figure 3: In vivo magnetic drive laparoscopic robots 


\subsubsection{Suction-based Robot}

The suction based HeartLander crawler robot shown in Fig. 4(a) is developed in [50] for navigation and fine positioning within intracardial environment. This is a tethered robot with two suction grippers - front and rear - and actuation wires. The robot moves using cycling inchworm like gait of extension and retraction. It uses suction pressure to grip the pericardium with the rear suction gripper and extends the body by actuating front body forward using the drive wires. Then it grips the pericardium using the front gripper, releases the rear gripper and retracts the rear body towards the front gripper. During the path tracking the surgeon defines the final goal point, the robot then autonomously generates an intermediate goal point located 'lookahead distance' ahead from the robot position. When the robot achieves the intermediate goal, the robot repeats the previous process until it is near to the final goal point; it then switches to fine-positioning control mode. This is the only in-vivo robot which had semiautonomous path-tracking feature [50]. Another suction-based robot 415 developed for abdominal cavity in [51] shown in Fig. 4(b) uses the abdominal wall for movement surface.

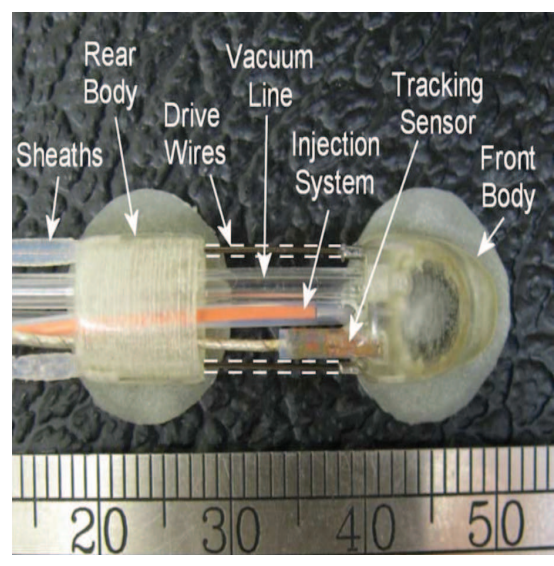

(a) HeartLander crawling robot [50]

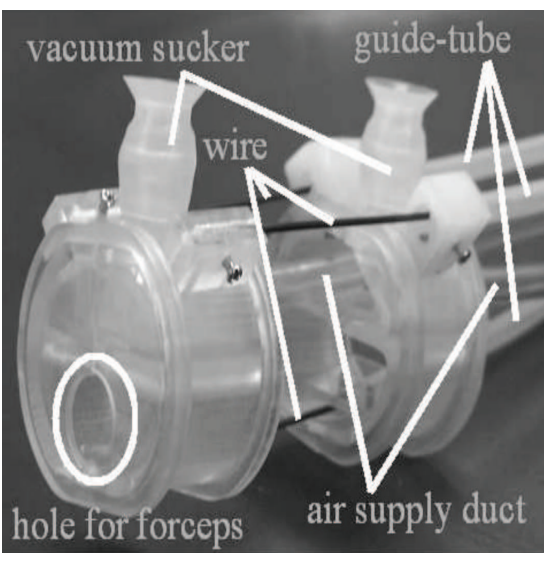

(b) Abdominal cavity robot [51]

Figure 4: Suction-based in vivo robots 


\subsection{Summary}

Table 2 presents comparison among various in-vivo robots. The in-vivo (porcine) tests of the robots show impressive results. Robots having exter${ }_{420}$ nal moving parts raises the concern of the safety of the internal soft tissue while moving over the abdominal organs (e.g. liver, spleen, intestine, and stomach). Wheeled robots reported in [10] moves over the abdominal organs without causing any visible tissue damage. However microscopic or internal damages have not been investigated. Also amount of tissue losses depends on tissue composition (e.g. fat, muscle), layer thickness and geometry, and histological characteristics $10 \mid$ Robots with magnetic drives move either along the abdominal wall $(42,47,48,43,44])$ or within the abdominal cavity over the abdominal organs ([49]). The external magnet could be fixed on a base [49] or operated by a human operator [42, 48] or attached to a robotic-arm [47]. Researchers ([49]) 430 reports that the precise robot positioning was not possible and requires further investigation. Although most of the developed robots are tethered for power and communication, wheeled robot presented in [10] relies on battery for power and communicates wirelessly. Though the array of robots presented in [43] are tethered for power and communication, an intra-abdominal zigbee wireless net-

${ }_{435}$ work is used to communicate between the anchoring frame and the robotic units. The in vivo porcine experiments using multiple cooperative robots [57, 10, 42 ] demonstrates the feasibility of using miniature laparoscopic robots to assist in surgical procedures. However, the robots are still in the in-vivo animal evaluation stage. Further improvements are necessary before a clinical trial is possible [57, 10, 42].

\section{Miniature in-vivo robot: Endoscopic robot}

\subsection{Background}

Gastrocamera, introduced in 1950s, enables the inspection of Gastro-intestinal (GI) track [58]. Nowadays, traditional probe endoscopy (PE) is an effective way 445 of diagnosis, treatment and surgery of esophagus, stomach, colon and upper 
small bowel. However rigidity and large diameter (11mm to $13 \mathrm{~mm}$ ) of PE make it inaccessible to major parts of small bowel and, patients found the procedures painful and uncomfortable [59]. In 2000, Given Imaging introduced wireless capsule endoscope (WCE) which has LEDs and a camera in front for the inspection

${ }_{450}$ of GI track. It is a non-invasive process and easy to perform and thus encourages the patients to go for the inspection for any potential GI disease [58]. Several capsules are developed targeting various parts of the GI track e.g. Pillcam SB for small bowel, Pillcam Colon for colon etc. [19]. However these capsules are moved by the aid of visceral peristalsis and do not have control over their move${ }_{455}$ ments and orientations which results low diagnostic accuracy [59]. Researches are ongoing to add self-propulsion capability, additional sensors and actuators with the WCE which has the potential to improve the diagnostic accuracy and extend interventional ability [12]. The robots designed and developed in this purpose are reviewed below.

460 6.2. Major robots built

A complete robot for capsule endoscopy consists of six modules: locomotion, power, vision, telemetry, localization and diagnosis/tissue manipulation tools [12, 59]. The robots can be classified based on each of the modules. However in this paper we focus on the locomotion of the robot. The robots built for capsule 465 endoscopes can be classified based on the locomotion principles/mechanisms as: 1) internal propulsion robot 2) external propulsion robot and 3) hybrid propulsion robot. Internal propulsion robot has the propulsion embedded with the robot whereas for external propulsion the propulsive force is generated by an external system. A hybrid propulsion robot uses more than one propulsion 470 mechanisms.

\subsubsection{Internal Propulsion Robot}

For an internal propulsion robot, the propulsion mechanism (actuators and corresponding mechanism) is totally onboard of the robot. Thus the robot has greater control on its mobility. The significant internal propulsion robots are 
reviewed below.

Legged Propulsion. BioRobotics Institute, Scuola Superiore Sant'Anna, Italy develops legged endoscopic capsule robots that extend from the 3-legged to 12legged endoscopic capsule robots (Fig. 5). Initially they design with SMA wire actuators and develop a 6-legged capsule robot prototype [60]. But design complexity and lack of durability of SMA wire compel them to choose BLDC as an actuator for their later versions of the robot. They develop 4-legged (diameter: 12mm, length: 40mm) [61], 8-legged (diameter: 12mm, length: 40mm) 62, 63] and 12-legged endoscopic capsule robots (diameter: 11mm, length: 25mm) [13]. The 12-legged endoscopic capsule robot has two leg set (LS), one near the front and one near the rear for successful locomotion. Every leg set has 6 legs. The rear LS has the primary function of producing thrust force, while the front LS is used for the dual purposes of bracing the capsule against unwanted backward motion as rear legs retract and also to help propel the capsule around curves. In order to move two LS independently two BLDC motors are used. The capsule can travel a distance equal to colon in a shorter time compare to the WCE [13].

Bio-mimetic/ Bio-inspired Propulsion. Several propulsion methods have been designed by mimicking biological systems. The developed propulsion methods are described below:

Earthworm-like / Inchworm-like propulsion robot: Several prototypes [65, 66, 67, 68] are developed on earthworm-like or inchworm-like propulsion principle based on piezo-actuators or SMA (shape memory alloy) spring. Fig. 6(a) shows one of them. The principle is cyclic expansion and compression of the actuator. All of the prototypes consist of one actuation mechanism (SMA or piezo), one or two bodies and insect-claw like directional passive clampers which clamps to prevent backward motion of the robot. The implemented module can travel $2 \mathrm{~mm} /$ cycle where the cycle time is $8 \mathrm{~s}$ [66]. This principle is similar to suction-based propulsion described before except that in earthworm principle passive clampers are used instead of the active suction cup. 


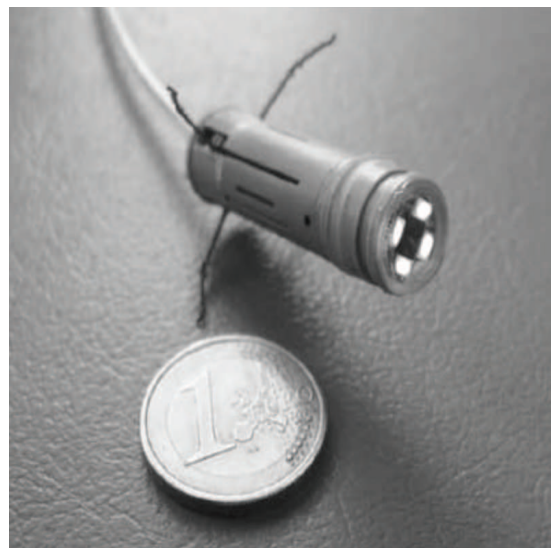

(a) SMA based four-legged robot 61]

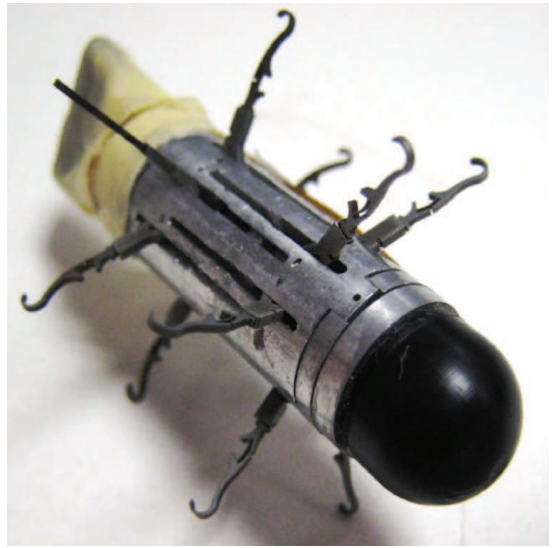

(c) Motor-driven twelve-legged robot 13

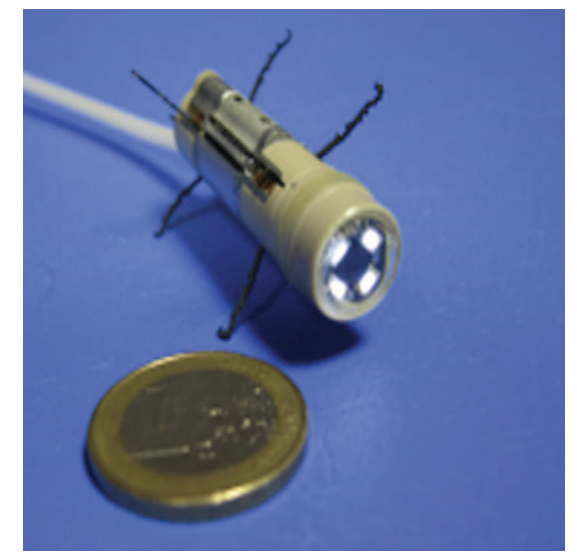

(b) Eight-legged robot 62]

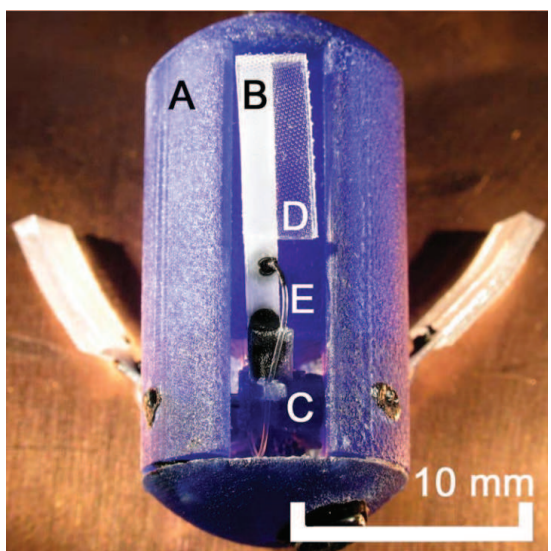

(d) Legged anchoring robot 64

Figure 5: Legged endoscopic robots 
A modular robot system (Fig. 6(b) based on inchworm-like locomotion is and the modules are assembled inside the GI track using permanent magnets placed at the end of each module. The assembled robot system moves by using opening/folding of the legs and the pushing/pulling of the connectors between the modules. Modeling and gait generation of a earth-worm like robot is presented in [70]. A motor-based capsule robot with inchworm propulsion principle is developed in [71] which is powered by wireless power transmission. A hollowcylinder-like three-dimensional coil is proposed for receiving the power. Ex-vivo experiment is performed using the developed prototype.

Cilia-based Robot: The cilia-based robot developed in [72, 73] using SMA 515 spring based actuators is shown in Fig. 6(c), It uses two sets of cilia controlled by two groups of SMA springs. By controlling the opening and closing of the cilia sets the robot can produce bidirectional movements.

Flagellar Swimming: A swimming mechanism [74, 75] mimics the swimming action of a flagellum. The micro-robot includes a main body and two tails, each having three segments of piezoelectric material. Traveling waves generated by exciting the segments of the tails with electricity of different phase and amplitude create the propulsive force of the robot. An up-scaled tail for the proposed robot is developed.

Paddling-based Propulsion Robot: This propulsion principle mimics a canoeist paddling a canoe [76, 77] which is a directed propulsion. A linear actuator with two cylinders: inner cylinder and outer cylinder, represents the canoeist. The robot (Fig. 6(d) consists of six legs placed radially to the robot and connected to the inner cylinder of the actuator through grooves. At the beginning of the cycle the legs remain folded and at the furthest most front position. Then the actuator slowly pulls the legs so that legs are protruded and clamp the intestinal wall and thus the legs along with cylinder are locked at one place. The actuator continues to pull the cylinder. As the cylinder is locked and cannot move, rest of the robot body moves forward. Then the actuator pushes the cylinder forward, the legs are released from the wall and folded inside and move 
forward without resistance and at the end the legs return to their initial position and ready to start the next cycle. By repeating this, the robot could move forward. The developed prototype is $13 \mathrm{~mm}$ in length and $30 \mathrm{~mm}$ in diameter and, $6.5 \mathrm{~mm} / \mathrm{s}$ velocity is achieved in the in-vitro test.

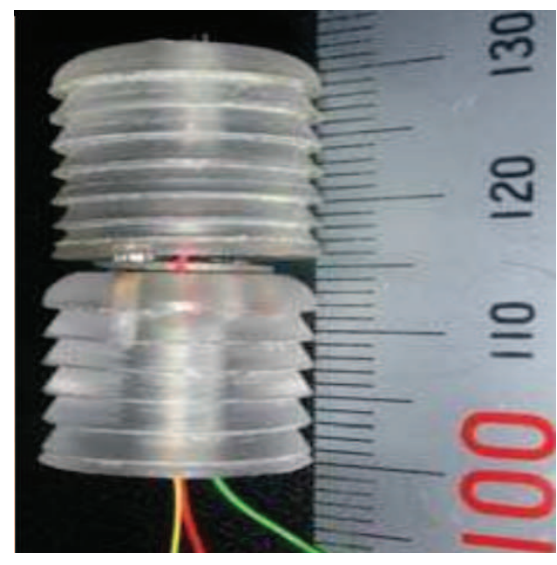

(a) Earth-worm propulsion robot 66

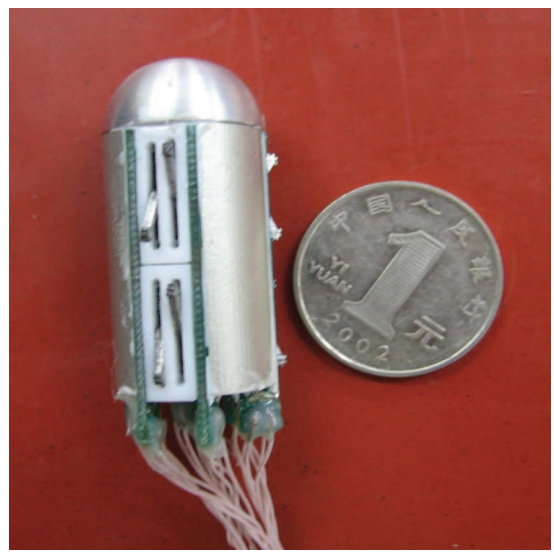

(c) Cilia-based propulsion robot 72

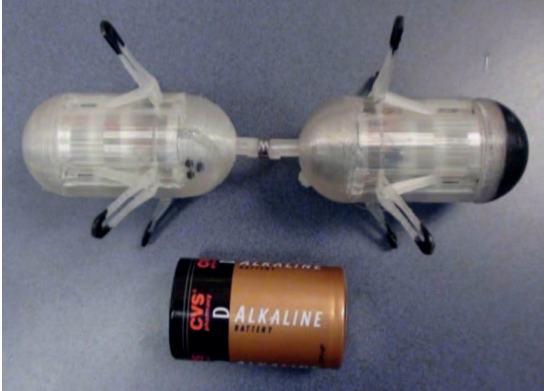

(b) Inchworm-like locomotion based modular robot [69]

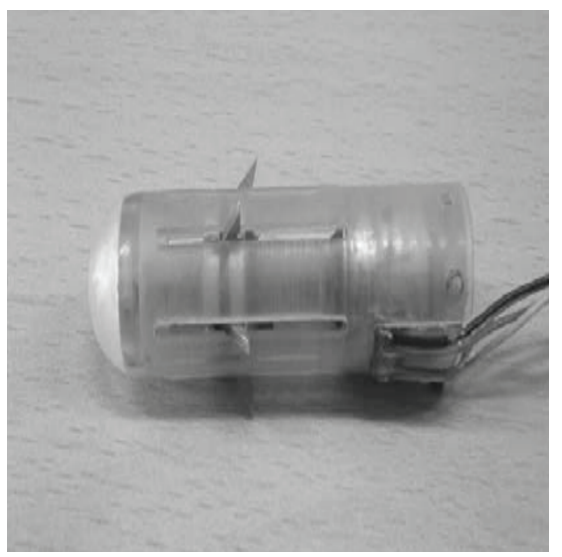

(d) Paddling based propulsion robot 77

Figure 6: Biomimetic endoscopic robots

Electrical Stimuli Propulsion Robot. This robot ( Fig. 7(a) is propelled by the 540 contraction of intestinal smooth muscle produced by electrical stimuli applied by two electrodes placed on the robot [78, 79, 80, 81]. The contraction creates 
sort of 'artificial' peristalsis which creates propulsive force and the robot moves opposite to the contraction end along the lumen. The propulsion is bidirectional depending on which electrode is activated. Average velocity achieved in the experiment is $2.91 \pm 0.99 \mathrm{~mm} / \mathrm{s}$ (forward) and $2.23 \pm 0.78 \mathrm{~mm} / \mathrm{s}$ (backward).

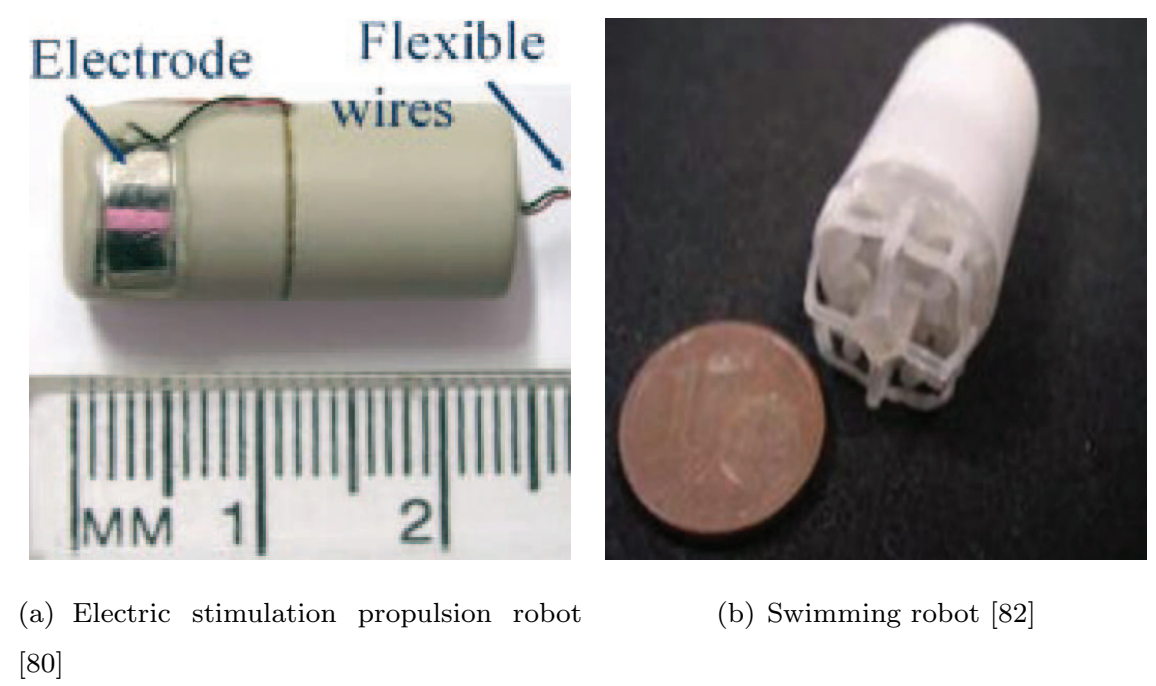

Figure 7: Electric stimulation propulsion robot and swimming robot

Vibratory Propulsion Robot. The Vibratory propulsion robot is investigated in [83, 84]. The robot has an eccentric mass inside the robot which is also the rotor of a motor. When the eccentric mass (rotor) rotates, it generates a centripetal force. The horizontal component of the force propels the robot. The developed robot is $28 \mathrm{~mm}$ long and $16 \mathrm{~mm}$ in diameter. The robot is tested on various surfaces (sand, liquid soap, solid foam and rubber hose) and moves with an average speed of $3 \mathrm{~cm} / \mathrm{s}$ (liquid soap) to $12 \mathrm{~cm} / \mathrm{s}$ (solid foam).

Swimming Robot. A swimming gastric capsule robot is shown in Fig. 7(b) To use this robot, the stomach has to be prepared with half litre of ingested polyethylene glycol (PEG) solution which enlarges the gastric region. The capsule performs 3D movement within the enlarged stomach with the help of 4 propellers run by four individual DC motors. It uses all four of its propeller while it advances in a rectilinear direction and for steering it uses only two of its 
four propellers. The weight/volume ratio of the capsule is made equal to PEG density $(1200 \mathrm{~kg} / \mathrm{m} 3)$ to make the robot enable to float, maintain the position \& orientation and observe the suspected region when the propellers are stopped. The robot is $15 \mathrm{~mm}$ in diameter and $40 \mathrm{~mm}$ in length and can be operated remotely by a human operator using joystick. The capsule is tested in a porcine stomach ex-vivo and maximum speed obtained is $21.3 \mathrm{~cm} / \mathrm{s}$ [85, 82].

A swimming robot modified from [82] is wirelessly powered in [86]. The embedded electronics and the motors of the robot are supplied upto $400 \mathrm{~mW}$ through inductive wireless power transmission. However only two motors can be operated at a time due to power limitation. Swimming robot of [85, 82] is improved in [87] and a complete functional system is developed consisting of an on-board locomotion system, a tele-operation console, a vision system and a real-time video transmission. A user can remotely control the swimming gastric robot through the user interface by only observing the video stream from the camera.

Internal Reaction Propulsion Robot. In this principle the robot moves by the reaction force caused by the movement of internal mass. These robots have no external legs or wheels [88, 89]. The structure of the principle is derived from [90]. A mass attached to the main object through a piezoelectric element, is made to move away from the main object rapidly and then to return to the initial position slowly with a sudden stop. The main object moves during the rapid motion and at the stopping moment of the mass and, remains stationary for the rest of the time. The object can move along a straight line by repeating the above process. Linearly moving mass and inverted pendulum which are described below can be used to generate the reaction force.

Using Linearly Moving Mass: In [91] linearly moving mass is used to generate robot motion. Here a permanent magnet is placed in a peripherally coil wound cylindrical body (capsule) (Fig. 8(a). By controlling current flow through the coil the permanent magnet can be moved back and forth within the capsule. The capsule robot completes each motion cycle in four steps. In the first two 


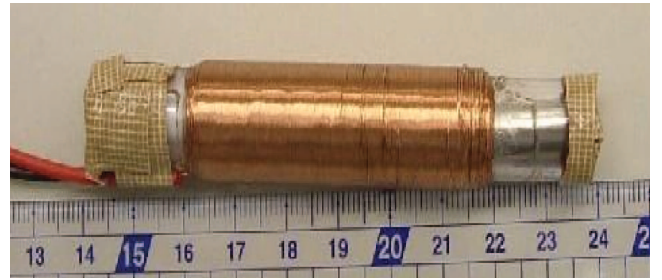

(a) Using linearly moving mass 91

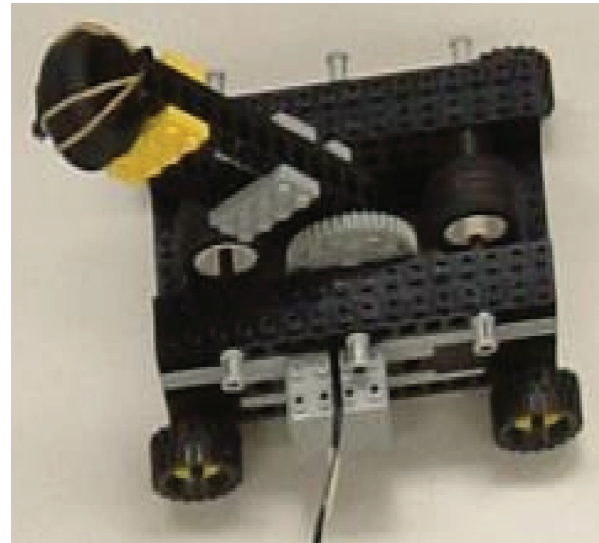

(b) Using inverted pendulum 92]

Figure 8: Internal reaction locomotion robot 
steps the magnet moves very fast and the reaction force caused the capsule to move in the opposite to the magnets motion. Again in the third and fourth steps the magnet moves slowly while the friction dominates over the reaction and the capsule remains stationary. By repeating the cycle the capsule can move in one dimension. Using Inverted Pendulum: Here the driving force is created by the reaction of the motion of an inverted pendulum. In [92] a pendulumdriven cart (Fig. 8(b) is developed and tested. The cart consists of passive wheels and a motor driven inverted pendulum on top of it which can move in the yz plane. The cart moves forward when the pendulum moves with the counter-clockwise high angular accelerated motion (step 1) and then low angular accelerated motion (step 2). The cart stays stationary when the pendulum moves with low accelerated angular motion counterclockwise (step 3) and then clockwise (step 4) while friction dominates over reaction force. At the end of step 4 the pendulum reaches to its initial position. By repeating the above steps the robot moves in a certain direction.

\subsubsection{External Propulsion Robot}

By using external propulsion the burden of having internal actuators are eliminated. The robot now have more space for other modules e.g. telemetry and diagnosis modules. External magnetic field that interacts with internal magnetic components is the typical source of propulsion in external propulsion robot. Most important external propulsion solutions are presented below:

External MRI Guided Propulsion. The static and RF magnetic field inherent in the MRI are used in this driving principle. Three swimming tails each consisting of three coils in a row are responsible for the propulsion of the robot. RF magnetic field provides power to generate alternating current in the coils of the tails. The alternating current interacting with the static magnetic field produces a waving movement and thus produces the propulsive force [95].

A magnetic guidance system similar to MRI is reported in [96] to control a capsule $(31 \mathrm{~mm} \times 11 \mathrm{~mm})$ to examine the stomach of 61 patients. An operator 


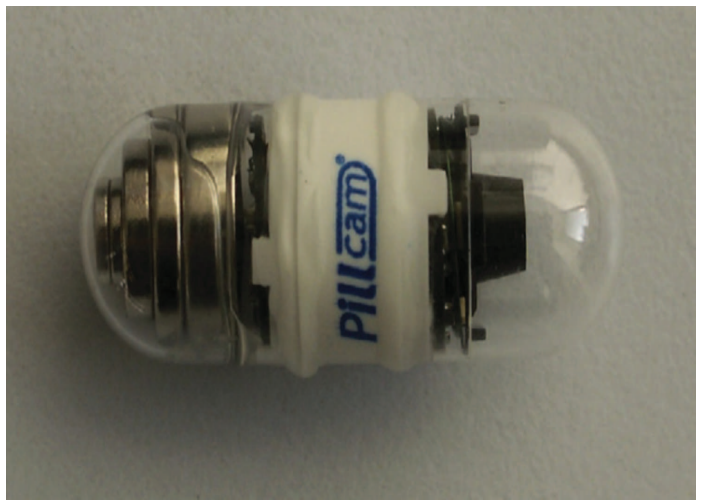

(a) Magnetic propulsion (NEMO) 93

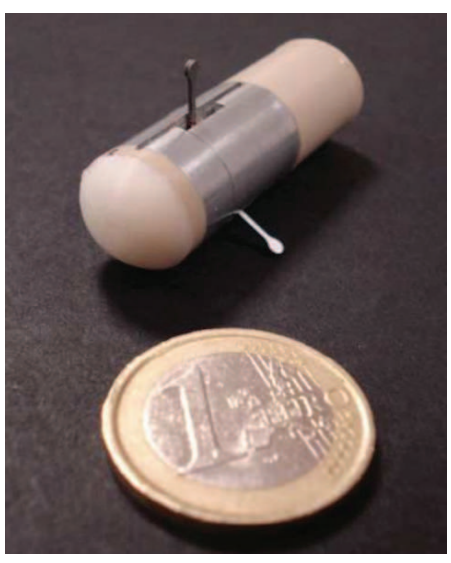

(b) Hybrid propulsion robot combining magnetic and legged propulsion 94]

Figure 9: Magnetic and hybrid propulsion endoscopic robots 
can control the movement of the capsule inside the stomach using two joysticks. Both gastroscopy and the capsule are used for the examination. The diagnostic results using gastroscopy and the capsule are comparable.

External Permanent Magnet Actuated Propulsion. The external permanent magnet could be operated by a human operator or by a motor or by a robot arm. Thay are described below:

Using hand-held/motorized magnet: Given Imaging develops a magnetic actuation system under the project NEMO (Nanobased Capsule-Endoscopy with Molecular Imaging and Optical Biopsy) (Fig. 9(a)). They modify their capsule to add a magnetic material inside. They use external hand-held plate permanent magnet to maneuver the capsule [97].

A magnetically actuated soft capsule endoscopic robot (diameter: $15 \mathrm{~mm}$, maximum/minimum length: $40 \mathrm{~mm} / 30 \mathrm{~mm}$ ) is developed in [98, 99]. It is actuated by a motorized external permanent magnet and it is able to navigate in three dimensions by rolling on the stomach surface. External attractive magnetic force is used to anchor the robot on a desired location and external magnetic torque is used to roll the robot to navigate on the stomach surface.

${ }_{635}$ The robot can be actively deformed in the axial direction using external magnetic actuation. Rolling locomotion and drug releasing experiment is performed in synthetic stomach. The robot is further developed in [100] and a magnetically actuated multimodal drug release mechanism is integrated where magnetic pulse frequency controls the drug release rate. The robot of [99] is modified to add biopsy functionality in 101] and ex-vivo biopsy experiments using pig stomach are performed. The robot carries and releases micro-grippers (tip-to-tip size $980 \mu \mathrm{m}$ ) inside the stomach and retrieves them after they grab tissue samples. Other researches on motorized magnet actuated propulsions include 102 and [103].

Using robotic navigation system: A magnetic shell coated capsule robot is actuated by a robotic magnetic navigation system developed by Stereotaxis in 104, 105]. The robotic system delivers a controlled magnetic field produced 
by two large coaxial permanent magnets arranged on both sides of the patients table. The magnetic shell coated capsule placed within the magnetic field can experience a 360 degree omnidirectional rotation according to the orientation of the controlled magnetic field. The position of the capsule robot is continuously monitored by the fluoroscopic scanner. The size of the commercially available capsule can further be decreased for this technique as there is no need of a battery here. But the Stereotaxis system is very expensive compared to the existing capsule endoscope and it could only be performed in the healthcare centres where the system is available.

A pilot study is performed to examine human stomach using a guidancemagnet-robot controlled capsule endoscope in [106]. The capsule endoscope $(28 \mathrm{~mm} \times 12 \mathrm{~mm})$ has a permanent magnet inside it. 34 healthy volunteers attended the study. The volunteers swallowed gas-producing powder to distend the stomach before swallowing the capsule. The examination was well accepted by the volunteers and it took $43.8 \pm 10 \mathrm{~min}$ to complete the examination. An actuator magnet is positioned using a Yaskawa Motoman robotic manipulator in 107. to propel a spherical device and a capsule-shaped device inside a PVC lumen during a proof-of-concept experiment. In their later work, similar actuator setup is used to control the position and orientation of a mockup capsule endoscope in fluid [108].

External Coils Actuated Propulsion. The Norika project team develops a capsule robot based on internal and external coils. It has three internal coils and is controlled by three external coils placed in a jacket worn by the patient [109].

An optimization algorithm is designed in [110] for the selection of most economical currents for the coils that generate external magnetic field for the magnetic propulsion. They propose three orthogonal coil pairs which can be placed around the abdomen. A small permanent magnet is enclosed into the capsule robot and the robot is propelled by the external orthogonal coils. Olympus develops a capsule with a permanent magnet placed inside it [109]. The capsule is controlled by a rotating magnetic field generated by three pairs of electro- 
magnets. It can be maneuvered using a spiral ridge wrapped around its body.

An electromagnetic 3D locomotion and steering system consisting of five pairs of solenoid components is developed in [111] for a capsule endoscope with permanent magnet to move within the digestive organs. The experiments are performed in a cubic chamber and tubular phantom filled with silicone oil. The capsule endoscope performs the translational, rotational and helical motions. An inflated bovine intestine is used in the ex-vivo experiment and the capsule 685 endoscope performs translational and rotational motions.

\subsubsection{Hybrid Propulsion Robot}

To reduce the inherent disadvantages of both internal and external propulsion, internal and external propulsions are combined in the hybrid propulsion. Magnetic and Motor Mechanism. A hybrid robot is developed in [112] where normal locomotion is achieved by external magnetic propulsion and fine orientation is achieved by utilising a internal mechanism. An internal motor is connected to a toothed gear and the gear is glued to two small internal magnets. The external permanent magnet is moved manually or by a simple hold and the capsule robot moves along the intestinal path with the motion of the external magnet. When fine orientation is necessary the external magnet is stopped and the internal motor is activated. The interaction of the internal magnets with the external magnet while the motor applies torque to the internal magnets allows the fine adjustment of the capsule robot position from 1.8 degree to 360 degree. The principle is called magnetic internal mechanism (MIM) and is tested in free space, in a phantom and in a Pig.

Magnetic and Legged Mechanism. A hybrid locomotion (Fig. 9(b) is proposed in [94] combining internal legged actuation mechanisms and external magnetic dragging. The developed capsule robot is moved by magnetic dragging with the help of internal permanent magnets and external magnetic field. Whenever it gets stuck in a collapsed area of GI track, internal legged mechanism is activated remotely. The legs distend the tissue and get the capsule robot out of the 
collapsed region. Then the capsule robot returns to magnetic dragging mode and starts moving normally. The hybrid capsule robot achieved $8 \mathrm{~cm} / \mathrm{min}$ speed in an in-vivo experiment [94].

Magnetic Torque Actuated Legged Mechanism. A magnetic torque actuated legged robot is developed in [113]. Actuation of two external permanent magnets causes the rotation of an internal permanent magnet. This rotation actuates a set of legs through an internal mechanism. These legs propel the robot while distending the intestinal wall. A scaled up prototype is developed and in-vitro experiments is conducted in a half-section intestine model where the robot moves with a speed of $5.7 \mathrm{~mm} / \mathrm{min}$.

\subsection{Summary}

Self-propelling robots for capsule endoscope are still in research stage. Both internal and external propulsions have disadvantages. These short-comings need to be addressed before they can be used clinically. The hybrid propulsion robot combines the internal and external propulsion to reduce few of their shortcomings. Tables 3 to 6 provide a comparison among the endoscopic robots. The advantage and disadvantages for various propulsion mechanisms are summarized below:

\subsubsection{Advantages and Disadvantages of Internal Propulsion Robot}

The internal propulsion robot can achieve precise position control compare to the external because of having the actuator on board. Some of them have the capability to distend lumen to facilitate the movement and to distend away the tissue from the camera lens [13]. However internal propulsion means there is a need of on-board power to drive the actuators. It is a challenge to accommodate the propulsion mechanism, power source (e.g. battery pack) and other relevant components in a capsule body while keeping the robot size within the limit of a standard capsule endoscope. Most of the internal propulsion robots have limbs or legs which may injure the internal soft tissue. A wider leg may reduce the 735 risk of tissue damage [62]. Moreover it is challenging to make a hermetically 
sealable robot which has legs or limbs. Most of the legged locomotion work was performed before 2011 and the research on this area decreased because of the onboard power requirement and design complexity. Innovations in energy storage or wireless energy transfer may revive the research area [114]. An inchworm principle based robot is developed in [71] which uses wireless power transmission to energise the robot.

\subsubsection{Advantages and Disadvantages of External Propulsion Robot}

The main advantage of the external propulsion is that it does not require onboard actuators and mechanisms and, thus requires less energy compare to internal propulsion. The robot still needs a magnetic component onboard which interacts with the external robot. However this magnetic component takes smaller space compare to the internal propulsion mechanism [115]. It is more likely that we will get a self-propelling capsule endoscope with external propulsion mechanism in a standard capsule endoscope size sooner than with internal propulsion mechanism. The robot can be made hermetically sealable as there are no external moving parts - i.e. no limbs or legs. However precise movement and control is not always possible for external magnetic propulsion because of nonlinearity of magnetic field [16]. Also tissue-distending or removal of tissue from the camera is not possible using this mechanism. There is a risk of getting stuck in a collapsed region inside the GI track which inspired to develop a hybrid robot in [94]. Furthermore MRI system [95, 96] and robotic navigation system (e.g. Stereotaxis [104, 105], Yaskawa Motoman [107, 108]) used for many external propulsion are expensive and bulky and, the control is complex. Thus external propulsion robot actuated by MRI or robotic navigation system may not be deployed outside the hospital or by a nonclinical person [107, 108].

\subsubsection{Advantages and Disadvantages of Hybrid Propulsion Robot}

A hybrid propulsion robot aims to overcome the short-comings of the external propulsion mechanism. The hybrid robot developed, uses external propulsion as primary propulsion. To achieve the fine positioning capability, the hybrid 
765 robot of [112] uses a two small internal magnets and one internal motor. To achieve the tissue distending capability, the hybrid robot of [94] uses an internal leg-mechanism. However to achieve additional functionality they introduce new mechanisms on-board which requires on-board powers to run.

\section{Conclusions and Future Trends} procedures, their usages are still in infancy. However they show promises of solving economic and social issues by reducing cost of health care and ensuring patient wellbeing. Though the external da-Vinci robot is performing surgical procedures quite successfully, there are still needs of adding further functionthe laboratories. One of the biggest challenges for miniature in-vivo robots is to develop a power-efficient, safe and miniature propulsion mechanism. Hybrid propulsion has the potential to bring break-through for in-vivo robots. Though there is a growing market for medical robotics, this field is still in its early stage. We might see the full strength of medical robots after few decades of collaborative research and development of the industry, health care providers and the universities.

The researchers are focused to build inexpensive, safer, compact, lightweight, autonomous and tele-operated robots for medical interventions/. The future of medical will be different from what it is now. In robot surgery modified and new instruments will continue to be added. The overall surgical system will become much smaller and flexible. A modular miniature co-operative in-vivo robot might change the surgery dynamics to a new direction. The robot system will be more integrated and intelligent. The combination of tele-operation and autonomous co-operative medical robot will enable advanced health care services (e.g. surgery, biopsy etc.) in remote places such as battle-field, natural disaster site, space missions etc. 
Table 1: Comparison of minimally invasive diagnosis and intervention robots based on key features

\begin{tabular}{|c|c|c|c|}
\hline \multirow{3}{*}{$\begin{array}{l}\text { Robot / } \\
\text { Criteria }\end{array}$} & \multirow{3}{*}{$\begin{array}{c}\text { External } \\
\text { large robot } \\
{[15,16,35]}\end{array}$} & \multicolumn{2}{|l|}{ Miniature in-vivo robot } \\
\hline & & In-vivo endoscopic & In-vivo laparoscopic \\
\hline & & robot $[13,19]$ & robot $[10,17,9]$ \\
\hline $\begin{array}{l}\text { Operating } \\
\text { anatomy }\end{array}$ & any & gastro-intestinal track & $\begin{array}{c}\text { abdominal cavity, } \\
\text { thoracic cavity }\end{array}$ \\
\hline $\begin{array}{c}\text { Clinical } \\
\text { applications }\end{array}$ & $\begin{array}{l}\text { surgery: general, } \\
\text { cardiothoracic, } \\
\text { orthopedic, neuro } \\
\text { gynaecologic etc. }\end{array}$ & diagnosis, biopsy & $\begin{array}{l}\text { surgery assistant: } \\
\text { vision, task. } \\
\text { biopsy }\end{array}$ \\
\hline $\begin{array}{l}\text { Robot } \\
\text { position }\end{array}$ & $\begin{array}{c}\text { outside } \\
\text { patient's body }\end{array}$ & $\begin{array}{c}\text { inside } \\
\text { patient's body }\end{array}$ & $\begin{array}{c}\text { inside } \\
\text { patient's body }\end{array}$ \\
\hline Size & $\begin{array}{l}\text { large robot } \\
\text { having multiple } \\
\text { robotic hands }\end{array}$ & $\begin{array}{c}\text { miniature - typical } \\
\text { diameter }<20 \mathrm{~mm} \text { and } \\
\text { length }<50 \mathrm{~mm} \text { ) } \\
\text { e.g. in }[13] \\
\text { diameter: } 11 \mathrm{~mm} \text {, } \\
\text { length: } 25 \mathrm{~mm}\end{array}$ & $\begin{array}{c}\text { miniature - typical } \\
\text { diameter }<20 \mathrm{~mm} \text { and } \\
\text { length }<100 \mathrm{~mm} \text {, } \\
\text { e.g. in [9] } \\
\text { diameter: } 15 \mathrm{~mm} \text { and } \\
\text { length: } 85 \mathrm{~mm}\end{array}$ \\
\hline $\begin{array}{l}\text { Large } \\
\text { operating } \\
\text { room }\end{array}$ & requires & $\begin{array}{l}\text { internal propulsions } \\
\text { do not require, } \\
\text { external propulsions } \\
\text { may require }\end{array}$ & $\begin{array}{c}\text { magnetic drive } \\
\text { may require, } \\
\text { other propulsions do not require }\end{array}$ \\
\hline $\begin{array}{l}\text { Currently } \\
\text { operating }\end{array}$ & $\begin{array}{l}\text { medical and } \\
\text { research labs }\end{array}$ & research labs & research labs \\
\hline Power & mains cable & battery, tethered & tethered \\
\hline
\end{tabular}


Table 2: Comparison among in-vivo laparoscopic robots based on key features

\begin{tabular}{|c|c|c|c|c|}
\hline $\begin{array}{l}\text { Robot / } \\
\text { Criteria }\end{array}$ & $\begin{array}{l}\text { Fixed base } \\
\text { robots [40] }\end{array}$ & $\begin{array}{l}\text { Wheeled } \\
\text { robots [9] }\end{array}$ & $\begin{array}{l}\text { Magnetic } \\
\text { drive robots [42] }\end{array}$ & $\begin{array}{l}\text { Suction-based } \\
\text { robots }[51,50]\end{array}$ \\
\hline Power & tethered & tethered & tethered & tethered \\
\hline $\begin{array}{l}\text { Operating } \\
\text { anatomy }\end{array}$ & $\begin{array}{l}\text { abdominal } \\
\text { cavity }\end{array}$ & $\begin{array}{c}\text { abdominal } \\
\text { cavity }\end{array}$ & $\begin{array}{l}\text { abdominal } \\
\text { cavity }\end{array}$ & $\begin{array}{l}\text { abdominal } \\
\text { cavity, } \\
\text { intra-cardial } \\
\text { environment }\end{array}$ \\
\hline Locomotion & pan and tilt & $\begin{array}{l}\text { wheeled } \\
\text { locomotion }\end{array}$ & $\begin{array}{l}\text { magnetic } \\
\text { locomotion }\end{array}$ & $\begin{array}{l}\text { inch-worm } \\
\text { like } \\
\text { locomotion }\end{array}$ \\
\hline $\begin{array}{c}\text { External } \\
\text { moving parts }\end{array}$ & yes & yes & no & yes \\
\hline $\begin{array}{c}\text { Large } \\
\text { operating } \\
\text { room }\end{array}$ & $\begin{array}{l}\text { does } \\
\text { not require }\end{array}$ & $\begin{array}{l}\text { does } \\
\text { not require }\end{array}$ & may require & $\begin{array}{l}\text { does } \\
\text { not require }\end{array}$ \\
\hline $\begin{array}{c}\text { Clinical } \\
\text { applications }\end{array}$ & $\begin{array}{c}\text { vision } \\
\text { assistant }\end{array}$ & $\begin{array}{c}\text { task } \\
\text { and vision } \\
\text { assistant, } \\
\text { biopsy }\end{array}$ & $\begin{array}{c}\text { vision } \\
\text { assistant }\end{array}$ & navigation \\
\hline Actuator & $\begin{array}{l}\text { brushless } \\
\text { DC motor }\end{array}$ & $\begin{array}{l}\text { permanent } \\
\text { magnet } \\
\text { DC motor }\end{array}$ & $\begin{array}{l}\text { external } \\
\text { solenoid }\end{array}$ & $\begin{array}{l}\text { vacuum } \\
\text { pressure }\end{array}$ \\
\hline $\begin{array}{c}\text { In-vivo / } \\
\text { Ex-vivo trials }\end{array}$ & $\begin{array}{c}\text { in-vivo } \\
\text { test (porcine) }\end{array}$ & $\begin{array}{c}\text { in-vivo } \\
\text { test (porcine) }\end{array}$ & $\begin{array}{c}\text { in-vivo } \\
\text { test (porcine) }\end{array}$ & $\begin{array}{c}\text { in-vivo } \\
\text { test (porcine) }\end{array}$ \\
\hline
\end{tabular}


Table 3: Comparison among endoscopic robots based on key features (continued..)

\begin{tabular}{|c|c|c|c|c|c|c|c|c|c|c|}
\hline $\begin{array}{c}\text { Criteria/ } \\
\text { Robot }\end{array}$ & $\begin{array}{c}\text { Size } \\
\text { (Diameter, } \\
\text { Length) } \\
\mathrm{mm} \\
\end{array}$ & Power & $\begin{array}{l}\text { Locomotion } \\
\text { speed } \\
(\mathrm{mm} / \mathrm{min})\end{array}$ & Actuator & $\begin{array}{c}\text { External } \\
\text { moving } \\
\text { parts }\end{array}$ & $\begin{array}{l}\text { Distend } \\
\text { tissue }\end{array}$ & $\begin{array}{l}\text { Precise } \\
\text { position } \\
\text { control }\end{array}$ & $\begin{array}{c}\text { Intended } \\
\text { area of } \\
\text { work }\end{array}$ & $\begin{array}{c}\text { Large } \\
\text { operating } \\
\text { room }\end{array}$ & $\begin{array}{c}\text { Practical } \\
\text { trial }\end{array}$ \\
\hline$\frac{6-\operatorname{legg}}{5}$ & $\begin{array}{c}\text { not } \\
\text { reported }\end{array}$ & tethered & $\begin{array}{c}\text { not } \\
\text { reported }\end{array}$ & $\begin{array}{l}\text { SMA } \\
\text { wires }\end{array}$ & exists & capable & possible & $\begin{array}{l}\text { small bowel, } \\
\text { colon }\end{array}$ & $\begin{array}{c}\text { not } \\
\text { required }\end{array}$ & no \\
\hline 4-legge & 12,40 & tethered & $\begin{array}{c}\text { 10-30 } \\
\text { (ex-vivo) }\end{array}$ & $\begin{array}{l}\text { BLDC } \\
\text { motor }\end{array}$ & exists & capable & possible & $\begin{array}{l}\text { small bowel, } \\
\text { colon }\end{array}$ & $\begin{array}{c}\text { not } \\
\text { required }\end{array}$ & ex-vivo \\
\hline 8-legged [62] & 12,40 & tethered & $\begin{array}{c}50 \\
\text { (in-vivo) }\end{array}$ & $\begin{array}{l}2 \text { BLDC } \\
\text { motors }\end{array}$ & exists & capable & possible & $\begin{array}{l}\text { small bowel, } \\
\text { colon }\end{array}$ & $\begin{array}{c}\text { not } \\
\text { required }\end{array}$ & $\begin{array}{l}\text { in-vivo, } \\
\text { LGI } \\
\text { phantom }\end{array}$ \\
\hline 12-legged [13] & 11,25 & battery & $\begin{array}{c}50 \\
\text { (LGI } \\
\text { phantom) }\end{array}$ & $\begin{array}{l}2 \text { BLDC } \\
\text { motors }\end{array}$ & exists & capable & possible & $\begin{array}{l}\text { small bowel, } \\
\text { colon }\end{array}$ & $\begin{array}{c}\text { not } \\
\text { required }\end{array}$ & $\begin{array}{l}\text { ex-vivo, } \\
\text { LGI } \\
\text { phantom }\end{array}$ \\
\hline anchoring $[64,117]$ & $\begin{array}{c}\text { not } \\
\text { reported }\end{array}$ & $\begin{array}{c}\text { not } \\
\text { reported }\end{array}$ & 0 & $\begin{array}{c}\text { SMA } \\
\text { wire }[117] \\
\text { motor [117] }\end{array}$ & exists & $\begin{array}{c}\text { not } \\
\text { capable }\end{array}$ & $\begin{array}{c}\text { not } \\
\text { possible }\end{array}$ & $\begin{array}{c}\text { small bowel, } \\
\text { colon [117] } \\
\text { esophagus [117] }\end{array}$ & $\begin{array}{c}\text { not } \\
\text { required }\end{array}$ & in-vitro \\
\hline
\end{tabular}


Table 4: Comparison among endoscopic robots based on key features (continued..)

\begin{tabular}{|c|c|c|c|c|c|c|c|c|c|c|}
\hline $\begin{array}{c}\text { Criteria/ } \\
\text { Robot }\end{array}$ & $\begin{array}{c}\text { Size } \\
\text { (Diameter, } \\
\text { Length) } \\
\text { mm }\end{array}$ & Power & $\begin{array}{l}\text { Locomotion } \\
\text { speed } \\
(\mathrm{mm} / \mathrm{min})\end{array}$ & Actuator & $\begin{array}{c}\text { External } \\
\text { moving } \\
\text { parts }\end{array}$ & $\begin{array}{l}\text { Distend } \\
\text { tissue }\end{array}$ & $\begin{array}{l}\text { Precise } \\
\text { position } \\
\text { control }\end{array}$ & $\begin{array}{c}\text { Intended } \\
\text { area of } \\
\text { work }\end{array}$ & $\begin{array}{c}\text { Large } \\
\text { operating } \\
\text { room }\end{array}$ & $\begin{array}{c}\text { Practical } \\
\text { trial }\end{array}$ \\
\hline $\begin{array}{c}\text { Earthworm like [66] } \\
1 \\
1\end{array}$ & 13,33 & tethered & $\begin{array}{l}8.5-14.7 \\
\text { (in-vitro) }\end{array}$ & $\begin{array}{l}\text { SMA } \\
\text { spring }\end{array}$ & exists & $\begin{array}{c}\text { not } \\
\text { capable }\end{array}$ & possible & $\begin{array}{l}\text { small } \\
\text { bowel, } \\
\text { colon }\end{array}$ & $\begin{array}{c}\text { not } \\
\text { required }\end{array}$ & in-vitro \\
\hline Cilia-based [72] & 15,35 & tethered & $\begin{array}{c}24 \\
\text { (in-vitro) }\end{array}$ & $\begin{array}{l}\text { SMA } \\
\text { spring }\end{array}$ & exists & $\begin{array}{c}\text { not } \\
\text { capable }\end{array}$ & possible & $\begin{array}{l}\text { small } \\
\text { bowel, } \\
\text { colon }\end{array}$ & $\begin{array}{c}\text { not } \\
\text { required }\end{array}$ & in-vitro \\
\hline $\begin{array}{l}\text { Paddling based [77] } \\
\qquad=8\end{array}$ & 13,30 & tethered & $\begin{array}{l}\text { 197-375 } \\
\text { (in-vitro) }\end{array}$ & $\begin{array}{c}\text { linear } \\
\text { actuator }\end{array}$ & exists & $\begin{array}{c}\text { not } \\
\text { capable }\end{array}$ & possible & $\begin{array}{l}\text { small } \\
\text { bowel, } \\
\text { colon }\end{array}$ & $\begin{array}{c}\text { not } \\
\text { required }\end{array}$ & $\begin{array}{l}\text { in-vitro } \\
\text { in-vivo }\end{array}$ \\
\hline Electrical stimuli [80] & $\begin{array}{l}\text { ovoid: } \\
\text { 15-23 dia, } \\
\text { tapered by } \\
28-40 \text { deg }\end{array}$ & $\begin{array}{l}\text { tethered } \\
\text { [80] } \\
\text { battery } \\
{[81]}\end{array}$ & $\begin{array}{c}186 \\
\text { (in-vivo) }\end{array}$ & $\begin{array}{c}\text { electrical } \\
\text { stimulation }\end{array}$ & $\begin{array}{l}\text { does } \\
\text { not } \\
\text { exist }\end{array}$ & $\begin{array}{c}\text { not } \\
\text { capable }\end{array}$ & possible & $\begin{array}{l}\text { small } \\
\text { bowel, } \\
\text { colon }\end{array}$ & not & $\begin{array}{l}\text { in-vitro } \\
\text { in-vivo }\end{array}$ \\
\hline Internal reaction [91] & 80,200 & $\begin{array}{l}\text { tethered [91] } \\
\text { battery [118] }\end{array}$ & $\begin{array}{c}1188[91] \\
\text { or, } 720 \\
{[118]}\end{array}$ & $\begin{array}{l}\text { internal coil [91] } \\
\text { or, linear } \\
\text { motor }[118]\end{array}$ & $\begin{array}{l}\text { does } \\
\text { not } \\
\text { exist }\end{array}$ & $\begin{array}{c}\text { not } \\
\text { capable }\end{array}$ & possible & $\begin{array}{l}\text { small } \\
\text { bowel, } \\
\text { colon }\end{array}$ & $\begin{array}{l}\text { not } \\
\text { required }\end{array}$ & no \\
\hline
\end{tabular}


Table 5: Comparison among endoscopic robots based on key features (continued..)

\begin{tabular}{|c|c|c|c|c|c|c|c|c|c|c|}
\hline $\begin{array}{c}\text { Criteria/ } \\
\text { Robot }\end{array}$ & $\begin{array}{c}\text { Size } \\
\text { (Diameter, } \\
\text { Length) } \\
\text { mm }\end{array}$ & Power & $\begin{array}{l}\text { Locomotion } \\
\text { speed } \\
(\mathrm{mm} / \mathrm{min})\end{array}$ & Actuator & $\begin{array}{c}\text { External } \\
\text { moving } \\
\text { parts }\end{array}$ & $\begin{array}{l}\text { Distend } \\
\text { tissue }\end{array}$ & $\begin{array}{l}\text { Precise } \\
\text { position } \\
\text { control }\end{array}$ & $\begin{array}{c}\text { Intended } \\
\text { area of } \\
\text { work }\end{array}$ & $\begin{array}{c}\text { Large } \\
\text { operating } \\
\text { room }\end{array}$ & $\begin{array}{c}\text { Practical } \\
\text { trial }\end{array}$ \\
\hline Vibratory $[83,84]$ & 16,28 & $\begin{array}{c}\text { wireless } \\
\text { power } \\
\text { (inductive) }\end{array}$ & $\begin{array}{l}3 \mathrm{~cm} / \mathrm{s} \text { (liquid } \\
\text { soap), } \\
12 \mathrm{~cm} / \mathrm{s} \mathrm{(} \mathrm{solid} \\
\text { foam) }\end{array}$ & $\begin{array}{l}\text { vibratory } \\
\text { motor }\end{array}$ & $\begin{array}{l}\text { does } \\
\text { not } \\
\text { exist }\end{array}$ & $\begin{array}{c}\text { not } \\
\text { capable }\end{array}$ & possible & $\begin{array}{l}\text { small } \\
\text { bowel, } \\
\text { colon }\end{array}$ & $\begin{array}{c}\text { not } \\
\text { required }\end{array}$ & in-vivo \\
\hline Swimming $[85,82]$ & 15,30 & $\begin{array}{c}\text { battery } \\
{[85]} \\
\text { wireless } \\
\text { power [86] }\end{array}$ & $\begin{array}{c}100 \\
\text { (in-vitro) }\end{array}$ & $\begin{array}{l}4 \text { BLDC } \\
\text { motors }\end{array}$ & exists & $\begin{array}{c}\text { not } \\
\text { capable }\end{array}$ & possible & stomach & $\begin{array}{l}\text { not } \\
\text { required }\end{array}$ & $\begin{array}{l}\text { in-vitro } \\
\text { in-vivo }\end{array}$ \\
\hline $\begin{array}{l}\text { MRI guided } \\
\text { propulsion[95] }\end{array}$ & $\begin{array}{l}\text { complete } \\
\text { prototype } \\
\text { was not } \\
\text { developed }\end{array}$ & $\begin{array}{l}\text { wireless } \\
\text { power }\end{array}$ & $\begin{array}{c}\text { complete } \\
\text { prototype } \\
\text { was not } \\
\text { developed }\end{array}$ & $\begin{array}{l}\text { magnetic } \\
\text { fields } \\
\text { of MRI }\end{array}$ & exists & $\begin{array}{c}\text { not } \\
\text { capable }\end{array}$ & $\begin{array}{c}\text { not } \\
\text { possible }\end{array}$ & GI track & required & no \\
\hline $\begin{array}{l}\text { Robotic magnetic } \\
\text { navigation [104] }\end{array}$ & $\begin{array}{c}\text { capsule: } 11,26 \text {; } \\
\text { shell } 13,13\end{array}$ & $\begin{array}{c}\text { no } \\
\text { on-board } \\
\text { power }\end{array}$ & $\begin{array}{c}\text { not } \\
\text { reported }\end{array}$ & $\begin{array}{l}\text { magnetic } \\
\text { fields }\end{array}$ & $\begin{array}{l}\text { does } \\
\text { not } \\
\text { exist }\end{array}$ & $\begin{array}{c}\text { not } \\
\text { capable }\end{array}$ & $\begin{array}{c}\text { not } \\
\text { possible }\end{array}$ & GI track & required & $\begin{array}{l}\text { in-vivo, } \\
\text { plastic } \\
\text { phantom }\end{array}$ \\
\hline
\end{tabular}


Table 6: Comparison among endoscopic robots based on key features

\begin{tabular}{|c|c|c|c|c|c|c|c|c|c|c|}
\hline $\begin{array}{c}\text { Criteria/ } \\
\text { Robot }\end{array}$ & $\begin{array}{l}\text { Size } \\
\text { (Diameter, } \\
\text { Length) } \\
\text { mm }\end{array}$ & Power & $\begin{array}{l}\text { Locomotion } \\
\text { speed } \\
(\mathrm{mm} / \mathrm{min})\end{array}$ & Actuator & $\begin{array}{c}\text { External } \\
\text { moving } \\
\text { parts }\end{array}$ & $\begin{array}{l}\text { Distend } \\
\text { tissue }\end{array}$ & $\begin{array}{l}\text { Precise } \\
\text { position } \\
\text { control }\end{array}$ & $\begin{array}{c}\text { Intended } \\
\text { area of } \\
\text { work }\end{array}$ & $\begin{array}{c}\text { Large } \\
\text { operating } \\
\text { room }\end{array}$ & $\begin{array}{c}\text { Practical } \\
\text { trial }\end{array}$ \\
\hline $\begin{array}{c}\text { Motorized magnet } \\
\text { actuated propulsion [102] }\end{array}$ & $\begin{array}{l}\text { capsule: } \\
11,26 \\
\text { shell: } \\
11,10\end{array}$ & battery & $\begin{array}{l}\text { 90-190 } \\
\text { ex-vivo }\end{array}$ & $\begin{array}{l}\text { external } \\
\text { magnetic } \\
\text { field }\end{array}$ & $\begin{array}{l}\text { does } \\
\text { not } \\
\text { exist }\end{array}$ & $\begin{array}{c}\text { not } \\
\text { capable }\end{array}$ & $\begin{array}{c}\text { not } \\
\text { possible }\end{array}$ & $\begin{array}{l}\text { small } \\
\text { bowel }\end{array}$ & $\begin{array}{l}\text { not } \\
\text { required }\end{array}$ & $\begin{array}{c}\text { PVC } \\
\text { pipe, } \\
\text { ex-vivo }\end{array}$ \\
\hline $\begin{array}{l}\text { External coil } \\
\text { actuated propulsion [111] }\end{array}$ & 8,20 & none & 180 & $\begin{array}{c}\text { electro-magnetic } \\
\text { actuation }\end{array}$ & $\begin{array}{l}\text { does } \\
\text { not } \\
\text { exist }\end{array}$ & $\begin{array}{c}\text { not } \\
\text { capable }\end{array}$ & $\begin{array}{c}\text { not } \\
\text { possible }\end{array}$ & $\begin{array}{l}\text { small } \\
\text { bowel }\end{array}$ & $\begin{array}{l}\text { not } \\
\text { required }\end{array}$ & ex-vivo \\
\hline $\begin{array}{c}\text { Magnetic and } \\
\text { legged mechanism [94] }\end{array}$ & 14,44 & battery & $\begin{array}{c}100 \\
\text { (in-vitro) } \\
50 \\
\text { (in-vivo) }\end{array}$ & $\begin{array}{l}\text { magnetic } \\
\text { dragging, } \\
\text { BLDC } \\
\text { motor }\end{array}$ & exists & capable & $\begin{array}{c}\text { not } \\
\text { possible }\end{array}$ & $\begin{array}{l}\text { small } \\
\text { bowel, } \\
\text { colon }\end{array}$ & $\begin{array}{c}\text { not } \\
\text { required }\end{array}$ & $\begin{array}{l}\text { in-vitro, } \\
\text { ex-vivo, } \\
\text { in-vivo }\end{array}$ \\
\hline $\begin{array}{c}\text { Magnetic and } \\
\text { motor mechanism [112] }\end{array}$ & $15.6,48$ & battery & $\begin{array}{c}40 \\
\text { (in-vivo) }\end{array}$ & $\begin{array}{l}\text { magnetic } \\
\text { dragging, } \\
\text { motor }\end{array}$ & $\begin{array}{l}\text { does } \\
\text { not } \\
\text { exist }\end{array}$ & $\begin{array}{c}\text { not } \\
\text { capable }\end{array}$ & possible & $\begin{array}{l}\text { small } \\
\text { bowel, } \\
\text { colon }\end{array}$ & $\begin{array}{c}\text { not } \\
\text { required }\end{array}$ & $\begin{array}{l}\text { in-vitro, } \\
\text { ex-vivo, } \\
\text { in-vivo }\end{array}$ \\
\hline
\end{tabular}




\section{References}

[1] N. Hockstein, C. Gourin, R. Faust, D. Terris, A history of robots: from

795

[8] S. Ohno, C. Hiroki, W. Yu, Design and manipulation of a suction-based micro robot for moving in the abdominal cavity, Advanced Robotics 24 (12) (2010) 1741-1761. 
[9] M. E. Rentschler, J. Dumpert, S. R. Platt, K. Lagnernma, D. Oleynikov, S. M. Farritor, Modeling, analysis, and experimental study of in vivo wheeled robotic mobility, IEEE Transactions on Robotics 22 (2) (2006) $308-321$.

[10] S. R. Platt, J. A. Hawks, M. E. Rentschler, Vision and task assistance using modular wireless in vivo surgical robots, IEEE transactions on biomedical engineering 56 (6) (2009) 1700.

[11] D. Di Marco, G. Chow, M. Gettman, D. Elliott, Robotic-assisted laparoscopic sacrocolpopexy for treatment of vaginal vault prolapse, Urology 63 (2) (2004) 373-376.

[12] J. Toennies, G. Tortora, M. Simi, P. Valdastri, R. Webster, Swallowable medical devices for diagnosis and surgery: the state of the art, Proceedings of the Institution of Mechanical Engineers, Part C: Journal of Mechanical Engineering Science 224 (7) (2010) 1397-1414.

[13] P. Valdastri, R. Webster, C. Quaglia, M. Quirini, A. Menciassi, P. Dario, A new mechanism for mesoscale legged locomotion in compliant tubular environments, IEEE Transactions on Robotics 25 (5) (2009) 1047-1057.

[14] S. Lucak, Handbook of gastroenterologic procedures, Gastroenterology 130 (2) (2006) 617-618.

[15] P. Gomes, Surgical robotics: Reviewing the past, analysing the present, imagining the future, Robotics and Computer-Integrated Manufacturing 27 (2) (2011) 261-266.

[16] C. Tsui, R. Klein, M. Garabrant, Minimally invasive surgery: national trends in adoption and future directions for hospital strategy, Surgical endoscopy 27 (7) (2013) 2253-2257.

[17] M. E. Rentschler, S. R. Platt, K. R. Berg, J. Dumpert, D. Oleynikov, S. M. Farritor, Miniature in vivo robots for remote and harsh environ- 
ments, IEEE Transactions on Information Technology in Biomedicine 12 (1) (2008) 66-75.

[18] M. Rentschler, D. Oleynikov, Recent in vivo surgical robot and mechanism developments, Surgical endoscopy 21 (9) (2007) 1477-1481.

[19] A. Moglia, A. Menciassi, P. Dario, A. Cuschieri, Capsule endoscopy: progress update and challenges ahead, Nature Reviews Gastroenterology and Hepatology 6 (2009) 353-361.

[20] K. Ahmed, M. S. Khan, A. Vats, K. Nagpal, O. Priest, V. Patel, J. A. Vecht, H. Ashrafian, G.-Z. Yang, T. Athanasiou, et al., Current status of robotic assisted pelvic surgery and future developments, International Journal of Surgery 7 (5) (2009) 431-440.

[21] P. Dario, B. Hannaford, A. Menciassi, Smart surgical tools and augmenting devices, IEEE Transactions on Robotics and Automation 19 (5) (2003) $782-792$.

[22] A. Lehman, N. Wood, J. Dumpert, D. Oleynikov, S. Farritor, Robotic natural orifice translumenal endoscopic surgery, in: IEEE International Conference on Robotics and Automation, 2008, pp. 2969-2974.

[23] G. H. Ballantyne, Robotic surgery, telerobotic surgery, telepresence, and telementoring, Surgical Endoscopy and Other Interventional Techniques 16 (10) (2002) 1389-1402.

[24] B. Cheon, E. Gezgin, D. K. Ji, M. Tomikawa, M. Hashizume, H.-J. Kim, J. Hong, A single port laparoscopic surgery robot with high force transmission and a large workspace, Surgical endoscopy 28 (9) (2014) 2719-2729.

[25] M. Rentschler, J. Dumpert, S. Platt, S. Farritor, D. Oleynikov, Natu870 ral orifice surgery with an endoluminal mobile robot, Surgical endoscopy 21 (7) (2007) 1212-1215. 
[26] K. Bhattacharya, Kurt semm: A laparoscopic crusader, Journal of minimal access surgery 3 (1) (2007) 35.

[27] P. Mouret, How i developed laparoscopic cholecystectomy., Annals of the Academy of Medicine, Singapore 25 (5) (1996) 744.

[28] R. Satava, Surgical robotics: the early chronicles: a personal historical perspective, Surgical Laparoscopy Endoscopy \& Percutaneous Techniques $12(1)(2002) 6$.

[29] G. Ballantyne, F. Moll, The da vinci telerobotic surgical system: the virtual operative field and telepresence surgery, The Surgical clinics of North America 83 (6) (2003) 1293-1304.

[30] F. Corcione, C. Esposito, D. Cuccurullo, A. Settembre, N. Miranda, F. Amato, F. Pirozzi, P. Caiazzo, Advantages and limits of robot-assisted laparoscopic surgery: preliminary experience, Surgical Endoscopy and Other Interventional Techniques 19 (1) (2005) 117-119.

[31] K. Moorthy, Y. Munz, A. Dosis, J. Hernandez, S. Martin, F. Bello, T. Rockall, A. Darzi, Dexterity enhancement with robotic surgery, Surgical Endoscopy And Other Interventional Techniques 18 (5) (2004) 790795.

[32] Y. S. Kwoh, J. Hou, E. A. Jonckheere, S. Hayati, A robot with improved absolute positioning accuracy for ct guided stereotactic brain surgery, IEEE Transactions on Biomedical Engineering 35 (2) (1988) 153-160.

[33] W. P. Geis, H. C. Kim, E. Brennan, P. C. McAfee, Y. Wang, Robotic arm enhancement to accommodate improved efficiency and decreased resource utilization in complex minimally invasive surgical procedures, Studies in health technology and informatics (1996) 471-481.

[34] G. Ballantyne, P. Merola, A. Weber, A. Wasielewski, Robotic solutions to the pitfalls of laparoscopic colectomy, Osp Ital Chir 7 (2001) 405-412. 
[35] G. T. Sung, I. S. Gill, Robotic laparoscopic surgery: a comparison of the da vinci and zeus systems, Urology 58 (6) (2001) 893-898.

[36] A. R. Lanfranco, A. E. Castellanos, J. P. Desai, W. C. Meyers, Robotic surgery: a current perspective, Annals of surgery 239 (1) (2004) 14.

[37] http://www.davincisurgery.com/, accessed: 24.01.2014.

[38] M. E. Rentschler, J. Dumpert, S. R. Platt, D. Oleynikov, S. M. Farritor, K. Iagnemma, Mobile in vivo biopsy robot, in: 2006 IEEE International Conference on Robotics and Automation, 2006, pp. 4155-4160.

[39] A. Forgione, In vivo microrobots for natural orifice transluminal surgery. current status and future perspectives, Surgical Oncology 18 (2) (2009) $121-129$.

[40] A. C. Lehman, M. E. Rentschler, S. M. Farritor, D. Oleynikov, The current state of miniature in vivo laparoscopic robotics, Journal of Robotic Surgery 1 (1) (2007) 45-49.

[41] D. Oleynikov, S. M. Farritor, M. E. Rentschler, S. R. Platt, J. Dumpert, et al., Surgical camera robot, uS Patent 7,339,341 (2008).

[42] A. C. Lehman, K. A. Berg, J. Dumpert, N. A. Wood, A. Q. Visty, M. E. Rentschler, S. R. Platt, S. M. Farritor, D. Oleynikov, Surgery with cooperative robots, Computer Aided Surgery 13 (2) (2008) 95-105.

[43] G. Tortora, P. Dario, A. Menciassi, Array of robots augmenting the kinematics of endocavitary surgery, IEEE/ASME Transactions on Mechatronics 19 (6) (2014) 1821-1829.

[44] G. Tortora, A. Dimitracopoulos, P. Valdastri, A. Menciassi, P. Dario, Design of miniature modular in vivo robots for dedicated tasks in minimally invasive surgery, in: IEEE/ASME International Conference on Advanced Intelligent Mechatronics (AIM), 2011, pp. 327-332. 
[45] C. Castro, A. Alqassis, S. Smith, T. Ketterl, Y. Sun, S. Ross, A. Rosemurgy, P. P. Savage, R. D. Gitlin, et al., A wireless robot for networked laparoscopy, IEEE Transactions on Biomedical Engineering 60 (4) (2013) 930-936.

[46] C. Castro, S. Smith, A. Alqassis, T. Ketterl, Y. Sun, S. Ross, A. Rosemurgy, P. P. Savage, R. D. Gitlin, et al., Marvel: A wireless miniature anchored robotic videoscope for expedited laparoscopy, in: IEEE International Conference on Robotics and Automation (ICRA), 2012, pp. 29262931.

[47] I. Rivas-Blanco, P. del Saz-Orozco, I. Garcia-Morales, V. Muñoz, Robotic system for single incision laparoscopic surgery, in: IECON-38th Annual Conference on IEEE Industrial Electronics Society, 2012, pp. 2774-2779.

[48] B. S. Terry, Z. C. Mills, J. Schoen, M. E. Rentschler, et al., Single-portaccess surgery with a novel magnet camera system, IEEE Transactions on Biomedical Engineering 59 (4) (2012) 1187-1193.

[49] M. Nokata, S. Kitamura, T. Nakagi, T. Inubushi, S. Morikawa, Capsule type medical robot with magnetic drive in abdominal cavity, in: 2nd IEEE RAS \& EMBS International Conference on Biomedical Robotics and Biomechatronics, 2008, pp. 348-353.

[50] N. A. Patronik, T. Ota, M. A. Zenati, C. N. Riviere, A miniature mobile robot for navigation and positioning on the beating heart, IEEE Transactions on Robotics 25 (5) (2009) 1109-1124.

[51] S. Ohno, J. Tachikawa, W. Yu, Development of a micro mobile robot in the abdominal cavity, in: IEEE/RSJ International Conference on Intelligent Robots and Systems, 2009, pp. 4707-4711.

[52] T. Hu, P. K. Allen, T. Nadkarni, N. J. Hogle, D. L. Fowler, Insertable stereoscopic 3d surgical imaging device with pan and tilt, in: 2nd IEEE 
RAS \& EMBS International Conference on Biomedical Robotics and Biomechatronics, 2008, pp. 311-316.

[53] T. Hu, P. K. Allen, N. J. Hogle, D. L. Fowler, Insertable surgical imaging device with pan, tilt, zoom, and lighting, The International Journal of Robotics Research(2009).

[54] C. Hiroki, S. Ohno, Y. Ikemoto, W. Yu, A study on wire-wire driven abdominal cavity mobile micro robot, in: 2010 IEEE/RSJ International Conference on Intelligent Robots and Systems (IROS), 2010, pp. 28162821.

[55] D. Oleynikov, M. Rentschler, A. Hadzialic, J. Dumpert, S. Platt, S. Farritor, Miniature robots can assist in laparoscopic cholecystectomy, Surgical Endoscopy And Other Interventional Techniques 19 (4) (2005) 473-476.

[56] J. Hawks, J. Kunowski, S. Platt, In vivo demonstration of surgical task assistance using miniature robots, IEEE Transactions on Biomedical Engineering 59 (10) (2012) 2866-2873.

[57] S. Tognarelli, M. Salerno, G. Tortora, C. Quaglia, P. Dario, M. O. Schurr, A. Menciassi, A miniaturized robotic platform for natural orifice transluminal endoscopic surgery: in vivo validation, Surgical endoscopy 29 (12) (2015) 3477-3484.

[58] Y. Kusuda, A further step beyond wireless capsule endoscopy, Sensor Review 25 (4) (2005) 259-260.

[59] G. Ciuti, A. Menciassi, P. Dario, Capsule endoscopy: from current achievements to open challenges, IEEE Reviews in Biomedical Engineering 4 (2011) 59-72.

[60] S. Gorini, M. Quirini, A. Menciassi, G. Pernorio, C. Stefanini, P. Dario, A novel sma-based actuator for a legged endoscopic capsule, in: The First IEEE/RAS-EMBS International Conference on Biomedical Robotics and Biomechatronics, 2006, pp. $443-449$. 

and fabrication of a motor legged capsule for the active exploration of the gastrointestinal tract, IEEE/ASME Transactions on Mechatronics 13 (2) (2008) 169-179.

[62] M. Quirini, S. Scapellato, A. Menciassi, P. Dario, F. Rieber, C. Ho, S. Schostek, M. Schurr, Feasibility proof of a legged locomotion capsule for the GI tract, Gastrointestinal endoscopy 67 (7) (2008) 1153-1158.

[63] M. Quirini, S. Scapellato, P. Valdastri, A. Menciassi, P. Dario, An approach to capsular endoscopy with active motion, in: 29th Annual International Conference of the IEEE Engineering in Medicine and Biology Society, 2007, pp. 2827-2830.

[64] P. Glass, E. Cheung, M. Sitti, A legged anchoring mechanism for capsule endoscopes using micropatterned adhesives, IEEE Transactions on Biomedical Engineering 55 (12) (2008) 2759 - 2767.

[65] B. Kim, S. Lee, J. Park, J. Park, Design and fabrication of a locomotive mechanism for capsule-type endoscopes using shape memory alloys (SMAs), IEEE/ASME transactions on mechatronics 10 (1) (2005) 77-86.

[66] B. Kim, S. Park, C. Y. Jee, S.-J. Yoon, An earthworm-like locomotive mechanism for capsule endoscopes, in: 2005 IEEE/RSJ International Conference on Intelligent Robots and Systems, 2005, pp. 2997-3002.

[67] B. Kim, S. Lee, J. H. Park, J.-O. Park, Inchworm-like microrobot for capsule endoscope, in: IEEE International Conference on Robotics and Biomimetics, 2004, pp. 458-463.

[68] B. Kim, S. Park, J.-O. Park, Microrobots for a capsule endoscope, in: IEEE/ASME International Conference on Advanced Intelligent Mechatronics, 2009, pp. $729-734$. 
[69] L. Kim, S. C. Tang, S.-S. Yoo, Prototype modular capsule robots for capsule endoscopies, in: 2013 13th International Conference on Control, Automation and Systems (ICCAS), 2013, pp. 350-354.

[70] H. Fang, C. Wang, S. Li, K. Wang, J. Xu, A comprehensive study on the locomotion characteristics of a metameric earthworm-like robot, Multibody System Dynamics 35 (2) (2014) 153-177.

[71] J. Gao, G. Yan, Z. Wang, S. He, F. Xu, P. Jiang, D. Liu, Design and testing of a motor-based capsule robot powered by wireless power transmission, IEEE/ASME Transactions on Mechatronics (99), (2015).

[72] W. Li, W. Guo, M. Li, Y. Zhu, A novel locomotion principle for endoscopic robot, in: Proceedings of the 2006 IEEE International Conference on Mechatronics and Automation, 2006, pp. 1658-1662.

[73] Y. Feng, W. Li, M. Li, L. Sun, Structure optimization of the endoscopic robot ciliary leg based on dimensional analysis, in: IEEE International Conference on Robotics and Biomimetics, 2007, pp. 109-114.

[74] G. Kósa, M. Shoham, M. Zaaroor, Propulsion method for swimming microrobots, IEEE Transactions on Robotics 23 (1) (2007) 137-150.

[75] G. Kósa, P. Jakab, N. Hata, F. Jólesz, Z. Neubach, M. Shoham, M. Zaaroor, G. Székely, Flagellar swimming for medical micro robots: theory, experiments and application, in: 2nd IEEE RAS \& EMBS International Conference on Biomedical Robotics and Biomechatronics, 2008, pp. 258263.

[76] H. Park, S. Park, E. Yoon, B. Kim, J. Park, S. Park, Paddling based microrobot for capsule endoscopes, in: 2007 IEEE International Conference on Robotics and Automation, 2007, pp. 3377-3382.

[77] S. Park, H. Park, S. Park, B. Kim, A paddling based locomotive mechanism for capsule endoscopes, Journal of mechanical science and technology 20 (7) (2006) 1012-1018. 
[78] C. A. Mosse, T. N. Mills, M. N. Appleyard, S. S. Kadirkamanathan, C. P. Swain, Electrical stimulation for propelling endoscopes, Gastrointestinal endoscopy 54 (1) (2001) 79-83.

[79] S. Woo, J. Jang, E. Jung, J. Lee, Y. Moon, T. Kim, C. Won, H. Choi, J. Cho, Electrical stimuli capsule for control moving direction at the small intestine, in: Proceedings of the 24th IASTED International Conference on Biomedical Engineering, ACTA Press, 2006, pp. 311-316.

[80] S. H. Woo, T. W. Kim, J. H. Lee, P. U. Kim, C. H. Won, J. H. Cho, Implemented edge shape of an electrical stimulus capsule, The International Journal of Medical Robotics and Computer Assisted Surgery 5 (1) (2009) $59-65$.

[81] S. H. Woo, T. W. Kim, Z. Mohy-Ud-Din, I. Y. Park, J.-H. Cho, Small intestinal model for electrically propelled capsule endoscopy, Biomed Eng Online 10 (108) (2011) 1-20.

[82] G. Tortora, P. Valdastri, E. Susilo, A. Menciassi, P. Dario, F. Rieber, M. O. Schurr, Propeller-based wireless device for active capsular endoscopy in the gastric district, Minimally Invasive Therapy \& Allied Technologies 18 (5) (2009) 280-290.

[83] R. Carta, M. Sfakiotakis, N. Pateromichelakis, J. Thoné, D. Tsakiris, R. Puers, A multi-coil inductive powering system for an endoscopic capsule with vibratory actuation, Sensors and Actuators A: Physical 172 (1) (2011) 253-258.

[84] X. Zabulis, M. Sfakiotakis, D. P. Tsakiris, Effects of vibratory actuation on endoscopic capsule vision, in: 30th Annual International Conference of the IEEE on Engineering in Medicine and Biology Society, 2008, pp. 5901-5904.

[85] A. Menciassi, P. Valdastri, K. Harada, P. Dario, Single and multiple robotic capsules for endoluminal diagnosis and surgery, in: 2nd IEEE RAS 
\& EMBS International Conference on Biomedical Robotics and Biomechatronics, 2008, pp. 238-243.

[86] R. Carta, G. Tortora, J. Thoné, B. Lenaerts, P. Valdastri, A. Menciassi,

P. Dario, R. Puers, Wireless powering for a self-propelled and steerable endoscopic capsule for stomach inspection, Biosensors and Bioelectronics 25 (4) (2009) 845-851.

[87] I. De Falco, G. Tortora, P. Dario, A. Menciassi, An integrated system for wireless capsule endoscopy in a liquid-distended stomach, IEEE Transactions on Biomedical Engineering 61 (3) (2014) 794-804.

[88] H. Yu, Y. Liu, T. Yang, Closed-loop tracking control of a pendulumdriven cart-pole underactuated system, Proceedings of the Institution of Mechanical Engineers, Part I: Journal of Systems and Control Engineering 222 (2) (2008) 109-125.

[89] Y. Liu, H. Yu, T. Yang, Analysis and Control of a Capsubot, in: Proceedings of the 17th IFAC (International Federation of Automatic Control) World Congress, 2008, pp. 756-761.

[90] Y. Yamagata, T. Higuchi, A micropositioning device for precision automatic assembly using impact force of piezoelectric elements, in: 1995 IEEE International Conference on Robotics and Automation, 1995, pp. $666-671$.

[91] H. Li, K. Furuta, F. Chernousko, Motion generation of the capsubot using internal force and static friction, in: 45th IEEE Conference on Decision and Control, 2006, pp. 6575-6580.

[92] H. Li, K. Furuta, F. Chernousko, A pendulum-driven cart via internal force and static friction, in: 2005 International Conference Physics and Control, 2005, pp. 15-17.

[93] J. Keller, C. Fibbe, F. Volke, J. Gerber, A. C. Mosse, M. ReimannZawadzki, E. Rabinovitz, P. Layer, P. Swain, Remote magnetic control 
[100] S. Yim, K. Goyal, M. Sitti, Magnetically actuated soft capsule with the

of a wireless capsule endoscope in the esophagus is safe and feasible: results of a randomized, clinical trial in healthy volunteers, Gastrointestinal endoscopy 72 (5) (2010) 941-946.

[94] M. Simi, P. Valdastri, C. Quaglia, A. Menciassi, P. Dario, Design, Fabrication, and Testing of a Capsule With Hybrid Locomotion for Gastrointestinal Tract Exploration, IEEE/ASME Transactions on Mechatronics 15 (2) (2010) 170-180.

[95] G. Kósa, P. Jakab, F. Jólesz, N. Hata, Swimming capsule endoscope using static and RF magnetic field of MRI for propulstion, in: Proceedings of the IEEE International Conference on Robotics and Automation, 2008, pp. 2922-2927.

[96] J.-F. Rey, H. Ogata, N. Hosoe, K. Ohtsuka, N. Ogata, K. Ikeda, H. Aihara, I. Pangtay, T. Hibi, S.-E. Kudo, et al., Blinded nonrandomized comparative study of gastric examination with a magnetically guided capsule endoscope and standard videoendoscope, Gastrointestinal endoscopy 75 (2) (2012) 373-381.

[97] F. Volke, J. Keller, A. Schneider, J. Gerber, M. Reimann-Zawadzki, E. Rabinovitz, C. Mosse, P. Swain, In-vivo remote manipulation of modified capsule endoscopes using an external magnetic field, Gastrointestinal Endoscopy 67 (5) (2008) 121-122.

[98] S. Yim, M. Sitti, Design and analysis of a magnetically actuated and compliant capsule endoscopic robot, in: IEEE International Conference on Robotics and Automation (ICRA), 2011, pp. 4810-4815.

[99] S. Yim, M. Sitti, Design and rolling locomotion of a magnetically actuated soft capsule endoscope, IEEE Transactions on Robotics 28 (1) (2012) 183194. 
multimodal drug release function, IEEE/ASME Transactions on Mechatronics 18 (4) (2013) 1413-1418.

[101] S. Yim, E. Gultepe, D. H. Gracias, M. Sitti, Biopsy using a magnetic capsule endoscope carrying, releasing, and retrieving untethered microgrippers, IEEE Transactions on Biomedical Engineering 61 (2) (2014) $513-521$.

[102] M. Gao, C. Hu, Z. Chen, H. Zhang, S. Liu, Design and fabrication of a magnetic propulsion system for self-propelled capsule endoscope, IEEE Transactions on Biomedical Engineering 57 (12) (2010) 2891-2902.

[103] G.-S. Lien, C.-W. Liu, J.-A. Jiang, C.-L. Chuang, M.-T. Teng, Magnetic control system targeted for capsule endoscopic operations in the stomachdesign, fabrication, and in vitro and ex vivo evaluations, IEEE Transactions on Biomedical Engineering 59 (7) (2012) 2068-2079.

[104] F. Carpi, C. Pappone, Magnetic maneuvering of endoscopic capsules by means of a robotic navigation system, IEEE transactions on biomedical engineering 56 (5) (2009) 1482-1490.

[105] F. Carpi, N. Kastelein, M. Talcott, C. Pappone, Magnetically controllable gastrointestinal steering of video capsules, IEEE Transactions on Biomedical Engineering 58 (2) (2011) 231-234.

[106] Z. Liao, X.-D. Duan, L. Xin, L.-M. Bo, X.-H. Wang, G.-H. Xiao, L.-H. Hu, S.-L. Zhuang, Z.-S. Li, Feasibility and safety of magnetic-controlled capsule endoscopy system in examination of human stomach: a pilot study in healthy volunteers, Journal of interventional gastroenterology 2 (4) (2012) $155-160$.

[107] A. W. Mahoney, J. J. Abbott, Generating rotating magnetic fields with a single permanent magnet for propulsion of untethered magnetic devices in a lumen, IEEE Transactions on Robotics 30 (2) (2014) 411-420. 
[108] A. W. Mahoney, J. J. Abbott, Five-degree-of-freedom manipulation of

[114] P. R. Slawinski, K. L. Obstein, P. Valdastri, Capsule endoscopy of the future: Whats on the horizon?, World journal of gastroenterology: WJG 21 (37) (2015) 10528-10541.

[115] L. Liu, S. Towfighian, A. Hila, A review of locomotion systems for capsule endoscopy, IEEE Reviews in Biomedical Engineering 8 (2015) 138-151. 
1170 [116] I. Rahman, N. A. Afzal, P. Patel, The role of magnetic assisted capsule endoscopy (mace) to aid visualisation in the upper gi tract, Computers in biology and medicine 65 (2015) 359-363.

[117] P. Glass, E. Cheung, H. Wang, R. Appasamy, M. Sitti, A motorized anchoring mechanism for a tethered capsule robot using fibrillar adhesives for interventions in the esophagus, in: 2nd IEEE RAS \& EMBS International Conference on Biomedical Robotics and Biomechatronics, 2008, pp. $758-764$.

[118] H. Yu, M. Huda, S. Wane, A novel acceleration profile for the motion control of capsubots, in: 2011 IEEE International Conference on Robotics and Automation, 2011, pp. 2437-2442. 